1980

\title{
Age Differences in Attributions of Causality: Implications for Intellectual Assessment
}

Thomas R. Prohaska

Follow this and additional works at: https://scholarscompass.vcu.edu/etd

Part of the Psychology Commons

(C) The Author

\section{Downloaded from}

https://scholarscompass.vcu.edu/etd/5258

This Dissertation is brought to you for free and open access by the Graduate School at VCU Scholars Compass. It has been accepted for inclusion in Theses and Dissertations by an authorized administrator of VCU Scholars Compass. For more information, please contact libcompass@vcu.edu. 
School of Arts and Sciences

Virginia Commonwealth University

This is to certify that the dissertation prepared by Thomas R. Prohaska entitled Age Differences in Attributions of Causality: Implications for Intellectual Assessment has been approved by his committee as satisfactory completion of the dissertation requirements for the Degree of Doctor of Philosophy.

Iris A. Parham, Ph.D.

Assistant Professor of Psychology and Chairperson of Gerontology Program

Robert J. Hamm, Ph.D.

Associate Professor of Psychology

Donelson R. Forsyth, Ph.D.

Assistant Professor of Psychology

c

Jean G. Romaniuk, Ph.D.

Coordinator, Education and Evaluation,

Virgjnia Center on Aging

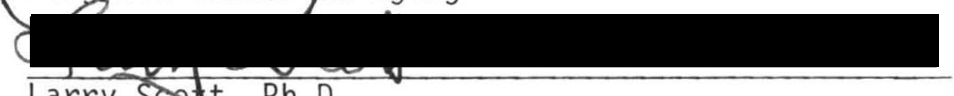

Larry Scatt, Ph.D.

Assistant Professor of Mathematical Sciences

WTliam A. Glynn, Ph.D.

Acting Dean, School of Ants and sciences

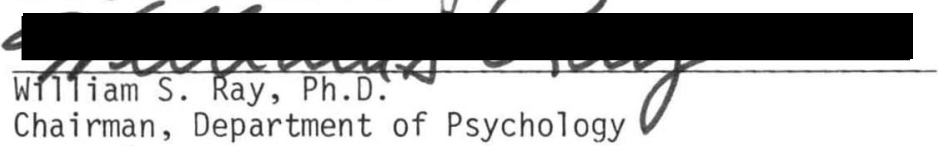

Chairman, Department of Psychology

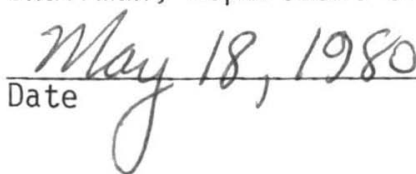


Age Differences in Attributions of Causality:

Implications for Intellectual Assessment

A dissertation submitted in partial fulfillment of the requirements for the degree of Doctor of Philosophy at Virginia Commonwealth University.

\section{By}

Thomas R. Prohaska

B.A. Roger Williams College 1974

M.A. Middle Tennessee State University 1975

Director: Iris A. Parham, Ph.D.

Assistant Professor of Psychology

and Chairperson of Gerontology Program

Virginia Commonwealth University

Richmond, Virginia

May, 1980 


\section{Acknowledgments}

I would like to express my appreciation to Dr. Ir is Parham, for her guidance throughout my graduate program and this investigation. I am also grateful to my dissertation committee, Doctors Robert Hamm, Jean Romaniuk, Donelson Forsyth, and Larry Scott for their help with components of this dissertation. I would like to extend special thanks to Debbie Lewis for her help with this manuscript.

This dissertation is dedicated to Helena M. Prohaska, my mother, whose love and guidance will never be forgotten. 
Table of Contents

Page

List of Tables................. . . . iv

List of figures . . . . . . . . . . . . . . v v

Abstract .................... . . . vi

Introduction ..................... 1

Contextualism .................. 6

Learned Helplessness . . . . . . . . . . . . . . . . . . 14

Attributional Reformulation of Learned Helplessness . . 20

Purpose of Study ................ 32

Hypotheses .................... 35

Method ..................... . . . 37

Subjects ..................... 37

Materials..................... 37

Attribution Questionnaires . . . . . . . . . . 39

Procedure ..................... . . . 40

Prior Test Information .............. . . . . 42

Exposure to Noncontingent Failure ......... . 43

Post Measures and Debriefing ............ . 43

Summary Condition Interventions.......... . . 44

Analyses...................... 45

Results ..................... . . . 46

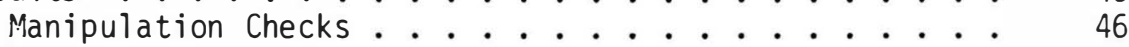

Hypotheses I ................... 50

Hypotheses II .................. 55

Hypotheses III . . . . . . . . . . . . 59

Discussion................... 71

References .................... 81

Appendices .................... 88

Vita ................... 111 
List of Tables

Table

Page

1. a. Results of the Age by Condition Analysis of

Variance to Question: "To What Extent Did

Your Effort Play A Part In The Outcome?". . . . . .

b. Results of the Age by Condition Analys is of

Variance to Question: "To What Extent Did

Your Intellectual Ability Play A Part In The

Outcome?" . . . . . . . . . . . . .

2. Heans to Effort Item After Failure for Ability and Effort Manipulation Groups. . . . . . . .

3. Results of the Age by Condition Analysis of Variance to Question: "Would You Evaluate Your Score as a Success or Failure?". . . . . . 51

4. Results of ANOVA on Age Differences to the Ten Items in the Post-Failure Attribution Questionnaire

5. ANOVA Age Differences in Need for Achievement...

6. Within Age Linear Contrasts to Mean Responses in the Ability and Effort Attribution Questions

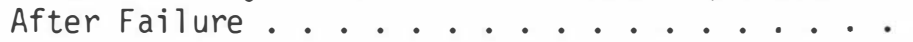

7. Mean Scores by Age and Condition in the Reasoning, Hidden Patterns, and Paper Folding Tests. . . . .

8. Between and Within Age Linear Contrasts on Mean Scores in the Reasoning, Hidden Patterns, and Paper Folding Tests ........... .

9. Age by Condition Analysis of Variance on the Reasoning, Hidden Patterns, and Paper Folding Tests ................. .

10. Age by Failure Group Analys is of Variance on the Reasoning, Hidden Patterns, and Paper Folding Tests 
List of Figures

Fi gure

Page

1 Weiner's Attributional Model of Achievement Motivation....................... 29

2 Research Design ................ 41

3 Age by Condition Plot of Test Scores-Reasoning. . . 60

4 Age by Condition Plot of Test Scores-Hidden

Patterns......................... 61

5 Age by Condition Plot of Test Scores-Paper Folding.................... 
Abstract

The present investigation was designed to test the hypotheses that failure experienced by the individual in a testing situation is moderated by causal attributions and these attributions influence subsequent test measures. The effect of manipulating cause (lack of effort or lack of ability) to response-independent failure and its relationship to scores on the Reasoning, Hidden Patterns, and Paper Folding Test, in younger and older persons was investigated. The same measures were assessed in a group that experienced the same response-independent-failure but with no explanation offered as to the cause for the failure, a group that was not given any information concerning the outcome, and a control group that did not experience the response-independent-failure.

Analysis of results indicated that younger subjects obtained significantly higher scores than older subjects on all three subtests. A significant age by condition effect in results from the Paper Folding Test was also found. The failure-ability group showed lower scores than the failure-effort group for both age categories. The two nonmanipulated-attribution groups were lower than the failure-effort group for the elderly, and were higher than the failure-ability group for younger subjects. The results supported the hypotheses that elderly individuals may demonstrate lower cognitive scores in part, due to influences that are extraneous to cognitive assessment. Implications of the results for elderly cognitive assessment were discussed. 


\section{Introduction}

The origional underlying concept of intelligence was that of a universal, unchanging capacity expressed by the I.Q. (Hunt, 1961). However, early research in the area has usually found that a maximal level fo intellectual functioning is reached at some point in adul thood and that the characteristic age function involved irreversible decrement. This decrement has been found in verbal, performance, and full scale scores of the Wechsler Adult Intelligence Scale using cross-sectional methods (Doppelt \& Wallace, 1955). Similar patterns of decline have been found in cross-sectional research of the Primary Mental Abilities (Schaie, 1959).

Research investigators who hold the position that intellectual functioning is either stable with aging or that decrements found could be explained or reversed, have since found a number of reasons for some of the decrements found in elderly persons' intelligence scores. These explanations generally adhere to three categories: methodological complications, appropriateness of test (internal validity), and ability-extraneous-performancerelated factors.

Problems in methodology are exemplified by the crosssectional versus longitudinal approach to testing elderly 
persons. Cross-sectional methods in intelligence testing superficially magnify age decline (Schaie, 1965). Longitudinal findings of maintenance in performance on psychometric measures of intelligence over much of the life span, and recent findings of substantial cohort effects in such measures (Schaie \& Labouvie-Vief, 1974; Schaie, Labouvie \& Buech, 1973) have led to questioning the assumption that age differences in intelligence are attributable to age changes. Although longitudinal and various sequential methods have accounted for some decline found in intelligence scores in the aged, such methodological considerations have not accounted for all, and research in the area is still being conducted.

The second category of investigation mentioned was that associated with tests. The specific test used is crucial to what inferences and generalizations will be drawn. Many or all of the tests that this author is aware of were not specifically designed for assessment of intelligence in older individuals. Certainly the Stanford-Binet, Wechsler Adult Intelligence Scale, or the Primary Mental Abilities which are used most often when testing intelligence, were not developed for this purpose. Revision of norms for the above scales were developed to keep the I.Q. constant. These revisions, however, were not extended to older populations. It seems likely then, that cross-sectional, and, to a lesser degree longitudinal results, consistently showed intelligence, as measured by these instruments, declining during adulthood and even more so during later years of life (Riegel, 1976). Much of the subsequent research attempted to explain, modify, or reject these observations. Research on structural differences 
of intelligence in the aged was one such modification.

A classic example that indicated marked structural change in intelligence in older populations came from research with fluid and crystallized intelligence (Horn \& Cattell, 1966). Crystallized intelligence is assumed to be partially a result of experience and is largely due to subject-related differences in experiential processes associated with the course of acculturation (Horn, 1967). Fluid intelligence represents the interactions of basic physiological capacity with a set of subjects and culture invariant experiential antecedents with low meaningfulness. The life pattern of these abilities demonstrates indistinguishable differences at first. In adulthood, fluid intelligence shows a decline. Experience and learning accumulate throughout life; therefore crystallized intelligence increases throughout adulthood. The point to be made is that one of the major deficiencies in tests used (e.g., Wechsler Adult Intelligence Scales) is that they do not reflect developmental theory for the entire life span. Until tests are developed to account for this, declines will be observed.

The research of Horn and Cattell mentioned above was not the only research in which structural differences appeared. Fluid and crystallized factors could be thought of as structure change within a given subject. Research findings also indicate structural changes within the group representing older subjects. These effects are due to such factors as selective survival and terminal change. The basic argument in selective survival is that due to individual 
differences in length of life, a given population with increasing age becomes more and more homogeneous. The survival factors for the increasingly homogeneous group may correlate with factors in intelligence. Siegler and Botwinick (1979) showed the importance of selective subject attrition in understanding age changes in intellectual ability of the elderly. They found that over a period of 20 years and eleven test sessions, the subject attrition from session to session was selective leaving mainly the intellectually superior, as measured by the WAIS, individuals in the study.

Concerning terminal drop, it has been observed that in some cases intelligence drops considerably just before death (Riegel \& Riegel, 1972). Declines in elderly cognitive functioning may, in part, reflect this change. Unless the test being used to assess the older subject account for these structural and/or developmental changes, inaccurate intellectual declines with increasing age will continue to be observed. The tests must address variables such as selective survival, terminal change, fluid and crystallized structures, etc., to be of significant value in understanding intelligence in the aged.

A number of variables have been isolated that could be considered in the third category mentioned--ability-extraneousperformance-related factors. These factors are situational and motivational variables that have the potential of differentially restricting the aged in intellectual performance. These factors are also defined as extraneous to the definition of intelligence being employed. One such variable believed to inhibit optimal 
responding by the elderly is fatigue. One study addressing this variable is that of Furry and Baltes (1973). Their investigation attempted to determine the degree to which age differences in measured intellectual performance were indicative of either socalled true age differences in specific cognitive abilities, or due to the ability-extraneous-performance-related factor of fatigue. The results indicated that manipulation of pre-experimental fatigue had differentially lowered scores on the Primary Mental Abilities in the fifty-one to eighty year old age group. Pre-test fatigue resulted in significant interaction effects on three of the five P.M.A. subtests (Verbal Meaning, Reasoning, Word Fluency) for the elderly.

Cautiousness is another major situational variable that has been found to confound intelligence measures (Birkhill \& Schaie, 1975). There is a developing body of literature which suggests a relationship between increasing cautiousness or conservatism and increasing age. One of the earliest was that of Wallach and Kogan (1961). It was found, through their "life situations" scale, that the elderly require more certainty of outcome before risky alternatives are selected. The elderly, in comparison to younger controls, responsed in a more cautious or conservative way in making decisions. Botwinick (1966) revised the Wallach and Kogan scale to include life situations that elderly experience and found that age was stastically significant. The older subjects were more conservative or cautious in their decision than younger subjects. Variations due to sex, level of education, 
and the interaction of these variables were not statistically significant.

Explanations as to the cause of age differences in measures of cautiousness are given by Schaie, et. al., (Schaie, Lavouvie \& Buech, 1973; Schaie \& Labouvie-Vief, 1974) as an artifact of the failure to control for the effect of socio-cultural change or cohort differences. Atkinson (1958) also has developed a model of achievement motivation to account for age differences in cautiousnesses. According to this model, which is also somewhat situation specific, the fear of failure or a weak need to achieve may account for cautiousness and older subjects do not respond to reinforcers of success and failure.

This has been a brief review of the considerable effort recently directed to accommodate findings of inter- and intrasubject variability in intellectual functioning. Attention will now be directed toward a model that integrates the three categories delineated above.

\section{Contextualism}

One model that has potential to conceptually incorporate all the avenues of research concerning elderly intelligence is that of contextualism as defined by Labouvie-Vief and Chandler (1978). The basic premise of this approach is the view that inevitable and intricate relationships exist between knowledge and the personal, historical, and motivational context from which such knowledge emerged. It is an attempt to deal with dialectic organism-environment relations in intellectual functioning. 
Theorists have in the past, been aware of dialectic organismenvironment relationships, the importance of various context variables, and the plasticity in elderly intellectual functioning (Baltes \& Schaie, 1976; Baltes \& Willis, 1977). However traditionally these cultural or situational differences found in elderly assessment of intelligence were considered potential-error variance or difficult-to-control nuisance variables that obscure or alter what is considered true intellectual development. This can be seen in idealistic accounts of intellectual development as moving along some nomological path toward an ideal end state of optimal levels in cognition (Labouvie-Vief \& Chandler, 1978). Since intellectual development was thought of in a linear and progressive fashion, the variations observed in elderly intelligence were considered not true or normal development but rather pathological (Birren, 1964) or exogenous factors (Jarvik \& Cohen, 1973). The contextual model does not argue that there is a relationship between some decrements for some measures of intelligence and increasing age. It does question, however, that such a relationship ought to exist or that these interpretations must follow. The contextual model has developed criteria to be met before "ought" and "must" are taken as truths.

Any research which claims to have demonstrated irreversible age-related changes in cognitive competence should be able to demonstrate (1) that the comparison groups employed were not different on important dimensions that are not inherently related to advancing age; (2) that 
the behaviors sampled or assessment procedures employed were not unfairly biased against one of the comparison groups, and that the differences reported were in fact irreversible, as demonstrated by unsuccessful retraining efforts (Labouvie-Vief \& Chandler, 1978, p. 188).

If one were to interpret the research findings concerning methodological complications mentioned earlier, it becomes apparent that these criteria are not totally satisfied. Factors like cohort effects and poor health are different from aging per se and do systematically influence intellectual functioning. As a direct consequence of their years, rather than their chronological age, elderly individuals were exposed to different formative influences (e.g., education) and different history. Schaie's (1965) sequential strategies do address the issue of cohort and time effects by estimating the effects for these factors. Research showed cohort membership, rather than age, accounts for a major share of the variation between age groups (Schaie, 1965). This does satisfy the first contextual criterion in that some of the important dimensions that are inherently related to advancing age are investigated, thereby accounting for some variation. However, the second criterion is not addressed. No retraining was conducted to test for reversibility, and individual differences within the elderly groups were depicted as true differences instead of possible contextual or situational differences.

The area of test sampling complications and intelligence structure models have also to some extent addressed lower intellectual 
functioning in the elderly through a contextualistic model. As stated earlier, many or all of the tests of intelligence were not specifically designed for assessment of intelligence in older individuals. Therefore, questions of ecological validity become appropriate when measuring intelligence, especially in the latter end of the life span. Validity to date has been . . measures of cognition which have been validated in one particular age group or in the context of one age-specific developmental theory and may not necessarily maintain their validity if applied across distant age groups. There is, in fact, evidence to suggest that performance levels which first appear similar in distant age groups are less convincingly equivalent upon closer scrutiny. (Labouvie-Vief \& Chandler, 1977, p. 195)

If measures of elderly intelligence cannot be developed within a tautological theory that validly and accurately fits adult development, it should at least be sensitive to the situational-contextual variations that influence these scores. Again as the research focus in methodological complications discussed earlier, important dimensions that are inherently related to advancing age are being investigated through research of test sampling complications and intelligence structure models (e.g., fluid and crystallized structures). Research has found structural differences between age groups (Horn \& Cattell, 1966). 
It is now recognized to some extent, the predominant bias of tasks in favor of younger subjects and decrements may be less a function of the structural limitations in older individuals, but rather inappropriate, nonvalidated selection of criterion tasks. Although contextualistic issues were addressed such as questioning the comparability of comparison groups and confronting the issue of appropriateness of theoretical structure, remediation and individual differences within an age group has not been fully addressed.

The third area of research discussed earlier, ability extraneous performance related factors in elderly intellectual measures, has addressed some of the most important socio-cultural influences. Also, this line of inquiry has attended to contextualistic prerequisites. For instance, the question of appropriateness of comparison groups and important noncognitive interference factors that differentially restrict the elderly are explored such as anxiety (Labouvie-Vief \& Gonda, 1976), fatigue (Furry \& Baltes, 1973), cautiousness (Okun \& DiVesta, 1978), and reluctance to guess when not sure (Birkhill \& Schaie, 1975). The question of reversibility or remediating whatever might be the cause of presumptive deficient performance in intellectual functioning is also explored. Plasticity in functioning was demonstrated by research alleviating, to some degree, performance deficits on tests of speed (Hoyer, Labouvie, \& Baltes, 1973) and fluid intelligence (Labouvie-Vief \& Gonda, 1976; Plemons, Willis \& Baltes, 1978). It is to the area of situational plasticity that this paper will be directed. It will also be argued that it 
is the context of the situation that determines the variations and decrements in cognitive functioning rather than a theory of cognitive development.

Two studies will be reviewed in light of a contextual model to draw attention to some of these situational cues. Birkhill and Schaie (1975) investigated the effects of differential reinforcement of cautiousness upon intellectual performance in eighty-eight elderly. Cautiousness was manipulated by varying the reinforcement contingencies for risk taking (high and low) of omitted responses and incorrect responses. It was found that scores on the Primary Mental Abilities Test were significantly better for individuals exposed to low-risk conditions than those exposed to high-risk conditions. Instruction to guess when not sure of an answer resulted in better scores in the verbal meaning, space, and reasoning Primary Mental Abilities subtests when failure to register a response was not penalized. Another interesting finding was that there were no differences in scores between individuals in the low- and high-risk for guessing condition when omitted responses were penalized. Birkhill and Schaie (1975) interpret this as an indicator that, manifestations of cautiousness by elderly people may involve an adaptive process which allows them to avoid engaging in activities which they believe may end in failure (Birkhill \& Schaie, 1975, p. 582). Penalizing for omissions, no matter what the risk results in recognized failure and would involve recognition of personal inadequacies. Birkhill and Schaie suggested that it may have been the fear of failure that moderated omission 
responses in the elderly. Elderly people perform poorly on these cognitive tasks because of excessive cautiousness. The contextual cues of varying pretest instruction with respect to reinforcement of response omission and level of risk interacted with level of cautiousness in the elderly to account for some of the variation and deficits found. In this case, the contextual cues while being extraneous to the testing measures, resulted in influencing test scores. Awareness of these cues and how they interacted with the personal historical and motivational components of the individual (i.e., cautiousness) led to research which demonstrated an improvement of scores.

In the second study, Labouvie-Vief and Gonda (1976) conceptualized reduced intellectual performances as an experiential deficit that can be reversed by concentrating on the training of certain component skills. A measure of fluid intelligence was used to assess the effects of these training sessions. This has two important implications in the contextualistic model. First the study is using a structural model of intelligence that is more appropriate to elderly cognitive functioning and, therefore, more sensitive to true changes. Secondly, as mentioned earlier, fluid intelligence has been shown to decline with advancing age and is interpreted to indicate the degree of biological decrement in the elderly. The purpose of the study was to explore the utility of an environmental rather than biological deficit interpretation of aging decrements (Labouvie-Vief \& Gonda, 1976). The authors reasoned that the strongest test of the environmental experiential 
deficits position on a fluid test. An inductive reasoning test, the Letter Sets Test, was chosen for one of the dependent measures. Two other components assessed in the study were the effect of training upon not only the training task, but on transfer tasks as well, and examination of the long-term facilitative effects of the training as well. Training procedure was aimed at the modification of subjects' verbal self-monitoring during task performance. The three training procedures were: specific cognitive training devised to increase strategies or rules of planning; a specific anxiety training session designed to reduce anxiety; and an unspecific training session in which individuals worked on items with no specific instructions. The control was a no-training group. The results showed training effects with some generalizability across tasks as well as time. One finding was unexpected by the authors but consistent with contextualistic theory. The finding that general practice effects were more prominent than those of specific training was unexpected. It was predicted that the strongest training effects should be obtained in the two specific training groups--cognitive training and anxiety training. It was believed that the elderly were ineffective in problem solving mainly because they fail to produce task-enhancing strategies (Labouvie-Vief \& Gonda, 1976). It was also believed that the specific sessions provide these training strategies more so than the unspecific training group. The authors suggested the cause for this unexpected result was due to elderly ineffectively utilizing experimenter-imposed strategies. This is not inconsistent 
with contextualistic principles. The elderly may be at a disadvantage due to ineffective strategies to problem solving, but that does not mean the etiology of the problem is lack of knowledge concerning a specific strategy or anxiety. Rather the contextual variables may be individual or multiple problems that are more easily addressed in nonspecific training.

This contextualistic model as presented above was outlined to offer alternative explanations to the decrements of ten found in elderly cognitive functioning. Examples presented argued that the decrements found of ten reflect the historical origin and cultural context of the age groups rather than change as a result of age. The ecological validity has been questioned also. Most important, the likelihood of pronounced situational plasticity in elderly intellectual functioning has been made plausible. One area of investigation not mentioned that may be an abilityextraneous variable and a situational or contextual cue that differently restrict elderly cognitive functioning is learned helplessness. All the contextual prerequisites as outlined earlier will be tested for its appropriateness to elderly intellectual functioning in a learned helplessness model. However, since the purpose of this paper is to introduce learned helplessness as a contextual interference factor in elderly cognitive functioning, the history and theory of learned helplessness will be presented beforehand.

\section{Learned Helplessness}

The pehnomenon of "learned helplessness" was first studied systematically with animals (Seligman and Maier, 1967). These 
experiments have shown that exposure to uncontrollable events results in a subsequent disruption of learning and behavior. A variety of animals have exhibited this behavior. For example, Overmier and Seligman (1967) found that dogs exposed to inescapable, unavoidable shocks in one situation later failed to learn to escape shock in a different situation where escape was possible. The proposed explanation of these effects argues that when events are uncontrollable, the organism learns that its behavior and outcomes are independent, and that this learning produces the motivational, cognitive, and emotional effects of uncontrollability.

Seligman (1975) originally formulated the learned helplessness theory as beginning with a process of learning that outcomes are uncontrollable or independent of one's responses. Behaviorally, this will tend to diminish the initiation of responding to control the outcome; cognitively, it will produce a belief in the inefficacy of responding, and difficulty at learning that responding succeeds, and emotionally, when the outcome is traumatic, it will produce heightened anxiety, followed by depression. Generally put, the incentive to initiate voluntary responses to control outcome comes from the expectation that responding will produce that outcome. When a person or animal has learned that the outcome is independent of responding, the expectation that responding will produce the outcome wanes; therefore, response initiation diminishes. Subsequent learning on other tasks is also disrupted. Usually in helplessness research, a triadic design is used; one group receives as pretreatment an outcome that it can control by some response; another group is 
yoked (group receives same outcome pattern as the contingent group but the outcome is independent of behavior); and a third group receives no pretreatment. Later all three groups are tested on a new learning task. This triadic design provides a direct test that it is not the outcome itself, but learning that the outcome is uncontrollable that causes deficits in subsequent learning. Learning that an outcome is independent of a response makes it more difficult to learn later on. The response-outcome independence is learned actively and interferes with learning about contingencies that contradict it. As may be expected, the group that received contingent outcomes learned best in a subsequent task followed by the control, and lastly by the noncontingent or yoked group. The two most obvious questions that follow are: (1) Is there research with humans that support this? (2) Are the elderly at a particular disadvantage or more susceptible to learned helplessness, and why?

The typical human study consists of an individual receiving a training phase followed by a test phase. Much like the triadic design used with animals, subjects are exposed to a training task in which he/she receives contingent reinforcement, noncontingent reinforcement, or no treatment (control). The test phase examines the three groups in a different response contingent task. Deficits in learning, responding, or effect compared to control is indicative of learned helplessness.

In general, empirical studies with humans demonstrated that learned helplessness can occur. It has been found to cause a 
reduction in motivation to respond (Overmier \& Seligman, 1968; Hiroto \& Seligman, 1975), heightened emotionally (Roth \& Bootzin, 1974), and a learning disruption on subsequent task (Dweck \& Reppucci, 1973).

Inappropriate generalizations from an uncontrollable situation to a situation in which control is, in fact, possible is the focus of learned helplessness. Under what situations or conditions do inappropriate generalization, especially deficits in learning and responding occur? More important, are these conditions present in a testing situation and do they superfluously magnify age decline in elderly measures of intelligence?

The literature in learned helplessness contains abundant evidence that when humans are asked to find solutions to problems that are actually unsolvable and then introduced to a new task, their performance on the new task suffers (Hiroto, 1974; Hiroto \& Seligman, 1976; Roth \& Kubal, 1975). Dweck (1975) found that a failure experience with unsolvable problems leads to a learning impairment on subsequent solvable task performance in an achievement situation. Forty fifth-grade children were given successes (soluble block designs) by one adult (success experimenter) and failure (insoluble block designs) by another (failure experimenters). When given problems that were soluble, children who had previously received problems from the failure experimenter failed to complete problems administered. Shortly before this, they had solved almost identical problems from the success experimenter. Decrements in intellectual functioning were found in children who had the ability 
to do so. Plasticity in measures were determined to some extent by the presence of noncontingent failure with one experimenter and contingent response outcome in another experimenter. Individual tests of intelligence are usually given by one experimenter. Contextual cues of failure in the case by one experimenter (tester) developed an expectancy of failure to other areas of the test (soluble block design). This study does give support to the possibility that early unconditional failure in a testing situation can generalize to other sections of the test.

A reaction to the above study would point out that the testing situation does not necessarily result in noncontingent failure and feedback. Results from a study by Brown and Inouye (1978) indicated that helplessness effects can be obtained without directly experiencing the typical noncontingent failure. They reasoned that lowered performance expectations can result not only from direct failure experiences, but from vicarious experiences as well. Male college students observed a model fail at anagram tasks under three conditions of perceived similarity; presumed similarity in ability, assumed superiority, or no information concerning their competence. Results showed that modeled failure can produce helplessness effects and that this is mediated by perceived similarity in competence. Although a direct measure of learning was not assessed, subjects who perceived the unsuccessful model to be of comparable ability and those given no competence feedback persisted less throughout the tasks than subjects who perceived the model as less competent than themselves 
and control subjects who did not observe a model. These results give evidence that it is the cognition of "uncontrollability" rather than the direct experience of uncontrollability itself, that is critical for producing helplessness effects. Also of equal importance is the finding that this modeled helplessness effect is moderated through perceptions of similarity of competence. The implication is that individuals, young or old, do not have to experience failure in a testing situation to show the effects of learned helplessness. They can either observe a model who is perceived similar fail or they can bring to the test, self-perceptions of inability or failure. Self-perceptions about one's own ability then becomes critical. It may be that the elderly bring to the testing situation factors related to this perceived loss of ability and sense of general cognitive impairment. Schulz (1976, 1979) characterizes old age as a succession of meaningful losses, despite the pleasures and benefits which are also inherent for this age. A loss of one's job (retirement) for this age group represents a loss of responsibilities, occupational status, and a loss of a work role identity. Declining sensory capacities and physical abilities are also known or perceived losses. By now what is known about situational plasticity of intellectual functioning through the contextualistic model and knowledge of the parameters of learned helplessness, it becomes increasingly obvious that intellectual assessment of the elderly must also include measures of the individuals' mental health status. In fact, Abrahams (1976) criticizes existing gerontology research for 
neglecting to control for the mental health status of aged intelligence test subjects.

It would be a very simple adjustment in already existing elderly testing procedures to suggest additional measures of mental health status. It could help alleviate some of the contextualistic confounds. Although this would be a significant improvement in light of the contextualistic model, it is incomplete. The reported literature in learned helplessness to this point have indicated that deficits in learning, responding and motivation are constantly observed. Although a majority of these human studies have reported performance deficits, several studies (Roth \& Bootzin, 1974; Roth \& Kubal, 1975; Thornton \& Jacobs, 1972) have reported increases in performance or a facilitation effect. In a sense, learned helplessness is embedded in a contextualistic maze and before the possible effect of learned helplessness can be understood on intelligence scores, it has to be understood through attribution theory.

\section{Attributional Reformulation of Learned Helplessness}

As stated previously, not all findings in learned helplessness indicate deficits in responding. Roth and Kubal (1975) found that the relative significance of the experimental task has also been shown to influence the development of learned helplessness. Importance was manipulated by instructing college students that the training and test tasks were measures of scholastic aptitude and intelligence or merely puzzles. Subjects in the important conditions showed significantly greater helplessness as a result 
of being exposed to noncontingent reinforcement than subjects in the unimportant condition. However, they also predicted and found a curvilinear relationship between the amount of exposure to noncontingent reinforcement and learned helplessness. They found that a moderate degree of exposure will result in a greater degree of responding or facilitation, whereas more exposure resulted in deficits, due to learned helplessness. This study showed the hypothesis that the perceived importance of the experimental task and the amount of exposure to noncontingency are factors in the development of learned helplessness. Although the literature has found that tasks in intelligence tests may be less meaningful or attractive to older adults, questions should be directed to the relative importance an individual has placed on success of the task. If two people are failing part of a test, or perceive they have or will fail the variation between the two scores may be a function of the difference in importance each has placed in the test. Confounds have since been uncovered by Tennen and Ellen (1977) stating that the amounts of exposure to helplessness may have interacted with attribution instructions.

Recently, the learned helplessness hypothes is has been reformulated based on attribution theory (Abramson, Seligman \& Teasdale, 1978; Miller \& Norman, 1979). It is now believed that many of the inconsistencies found in the human learned helplessness research can be accounted for within the parameters of attribution theory. In summation of the effect in learned helplessness, Miller and Norman (1979) state that causal attributions to noncontingent 
failure that are internal, important, stable, and/or general are predicted to maximize the severity and generalization of learned helplessness. Alternatively, attributions to this same response independent failure that are external, unimportant, variable and/or specific will minimize deficits. An attributional interpretation of the displayed performance disparities after failure has been developed by other researchers (Weiner, Frieze, Kukla, Reed, Rest \& Rosenbaum, 1971). Weiner, et. a1. (1971) contends that ascription of failure in a testing situation can be categorized into four factors within two causal dimensions: internal-external locus of control and stability-instability. He stated that task difficulty was perceived to be external and stable, luck as external and unstable, ability as stable and internal and effort as internal and unstable. By combining the attributional reformulation of learned helplessness with the Weiner et. al. theory of causal attribution in a test failure situation, predictions about the effect of learned helplessness can be made. Given that the task or test is important to the person and given that the person perceives the results (failure) to be independent of their actions, the following are possible: When the failure is perceived to be a result of luck, (external and unstable) the attributional reformulation would predict no helplessness effect. When the failure is perceived to be a result of task difficulty, (external and stable) helplessness predictions would state no effect of helplessness due to externality. If the failure is seen as caused by the individual's lack of ability, (internal and stable) learned 
helplessness effects should be observed. Last of all, when the failure is seen as a result of lack of effort, (internal and unstable) helplessness effects should not be observed. The basic issue to learned helplessness effects is then a matter of where the person places the cause of failure. The situational plasticity of observed scores is a result, in part, of the attributions made in the testing situation.

The research seems to be in agreement with the above predictions. Following attributional theory as outlined above, Tennen and Eller (1977) hypothesized that attributions to ability would lead to helplessness, whereas attributions to task difficulty would lead to facilitation. They replicated Roth and Kubal's study with the addition of a double helplessness condition consisting of two groups of students. The first group was told that the tests were becoming "more difficult," while the second group was told that the tests were becoming "easier." When compared, the "easier" group showed helplessness deficits, while the "more difficult" group showed facilitation effects. The "more difficult" group when presented with continued failure could ascribe failure to the increased difficulty of the task while the "easier" group could not. This does give support to helplessness being mediated by the subjects' attributions.

Five other studies have investigated the role of subject perceived attribution of resulting task performance in the development of learned helplessness (Dweck, 1975; Dweck \& Reppucci, 1973; Klein, Fencil-Morse \& Seligman, 1976; Wortman, 
Panciera, Shusterman \& Hibscher, 1976; Hanusa \& Schulz, 1977). These studies have generally supported the attributional reformulation of learned helplessness. In an article reported previously (Dweck \& Reppucci, 1973) it was mentioned that children who had previously solved similar problems with a success experimenter had failed to complete problems by the failure experimenter. It was found that the subjects who showed the largest performance decrements were those who took less personal responsibility for the outcomes of their actions (helplessness) and who, when they did accept responsibility, attributed success and failure to presence or absence of ability rather than effort. As expected, subjects who placed emphasis on the role of effort determining the outcome tended to persist in the face of prolonged failure (Dweck \& Reppucci, 1973). In another related study, Dweck (1975) taught "naturally" occurring helplessness children to attribute failure to a lack of effort. This reattribution training resulted in improvements in task persistence and less helplessness than did a group treated with success-only experiences. Although it was not assessed, this success-only training may have resulted in attribution to luck or decreased task difficulty. However, both alternative attributions are considered external and therefore, are not expected to alleviate effects of learned helplessness. The revised model of learned helplessness now includes the following criteria. Exposure to or perceived cognition of response-outcome independence (failure) results in an attribution to explain these outcomes (failures). The attributions constructed 
determine the development, type, and generalization of learned helplessness deficits. Dimensions of internality and stability maximize while externality and unstability minimize them. The importance of the results is hypothesized to affect the intensity of deficits produced.

The attributions of effort and ability have different effects on cognitive measures in a failure situation. Failure attributions to ability will result in cognitive deficits while attributions of failure to effort tend to facilitate functioning. Implications for intellectual assessment of the elderly seem obvious. The situational cues that produce feelings of success or failure must be monitored. When feelings of failure arise, an attempt must be made to determine if attributions to failure are perceived as being a result of effort, ability, difficulty of task or luck. A post-test questionnaire concerning an individual's feelings of success or failure may be an appropriate monitoring device. As research findings indicated, the causal ascription individuals make determines the degree or presence of learned helplessness. If an individual is prone to attribute failure to a stable-internalglobal cause (ability), it can have detrimental effects on subsequent tasks resulting in superfluously lower scores. It would be interesting to replicate the Dweck research on attribution retraining, but with older-helplessness-prone, ability-attributed-failure individuals in an intelligence assessment setting. From a contextualistic view, this would address the issue of reversibility through retraining efforts. 
The question as to how learned helplessness could be conceived as an ability-extraneous variable that has the potential of influencing measures of intellectual functioning has been adequately outlined.

The next question to be answered is concerned with the contextual, historical, and situational cues that are extraneous to intellectual assessment but systematically affect attributions to success and failure. If there are age differences in attributions to perceived failure then clearly these distinctions could account for some differences in intellectual performance. Achievement motivation has been found to be one such variable. Weiner and Sierad (1974) reported research that was based on attributions outlined in Weiner et. al. (1971); effort, ability, task difficulty, and luck. After controlling for task difficulty and luck, he found that individuals with high achievement needs will attribute failure to a lack of effort. This resulted in an increase in performance. Individuals with low achievement needs, however, tend to attribute failure to lack of ability and resulted in a decrease in performance. The ability-effort dimension is in agreement with Abramson et. al. (1978) and Miller and Brown's (1978) learned helplessness attribution reformulation. Since ability attributions are internal and stable, learned helplessness deficits are maximized. Effort being internal but unstable or variable, the effect of noncontingent failure is minimized. The important point to be made about this study is that achievement needs determine to some extent ascription to failure. The relation is stated as follows: 
e

The presumed associations are: High achievement needs ascription of failure to a lack of effortincrease in performance, and low achievement needs-ascription of failure to a lack of abilitydecrease in performance (Weiner, 1974, p. 141). As stated previously Dweck and Reppucci (1973) found that children were unable to solve problems given by a failure experimenter, even though they were able to solve almost identical problems from the success experimenter. This study reported sex differences in persistence and emphasized the role of effort in determining the outcome of their behavior with this failure experimenter. Males displayed this characteristic to a greater extent than did females. This was linked to the possibility of differences in achievement motivation. In a study that supports the above findings, Weiner and Kukla (1970) reported differences between their high- and low-achievement-motive groups in the tendency to internally attribute failure to ability versus effort. They found that children beyond the fourth grade who were low in achievement motivation, were more likely to attribute failure to lack of ability while the high-achievement-motive group attribute failure to personal motivation more frequently than the low-achievement-oriented group.

Achievement motivation does mediate the ability-versus-effort attribution to some degree. Again, the implication for situational factors that could influence the resultant measures of intelligence become obvious. Individuals low in achievement motivation that 
experience or believe they experience noncontingent outcomes in a testing situation will likely attribute that failure to a lack of their own ability. This in turn would lead to a susceptibility for learned helplessness throughout the test. Results would then show decrements that are actually confounds and not reflective of the individual's true ability.

There are two last questions to address before accepting the proposal that learned helplessness is a contextual, abilityextraneous variable that has the potential to influence elderly performance during intellectual assessment. Is there evidence that elderly individuals have a lower need for achievement particularly in intellectual assessment? And are there any other antecedent variables that affect causal attributions to failure differentially by age.

Weiner (1974, p. 48) presents an attributional model of achievement motivation (see figure 1). Achievement needs is under the topic of individual differences and is one of $f$ ive possible antecedent categories in attributions to success and failure. According to this model, if age differences in any of these antecedents are found, this could change the causal ascription of the outcome. The effect of individual differences in achievement needs on attributions has been previously discussed. The literature on age differences in need for achievement is inconclusive. A small number of studies have indicated crosssectionally that indices of need for achievement motivation decreases with increasing age (Kuhlen \& Johnson, 1952; Smith, 1970; 
AN ATtRIBUTIONAL MODEL OF ACHIEVEMENT MOTIVATION

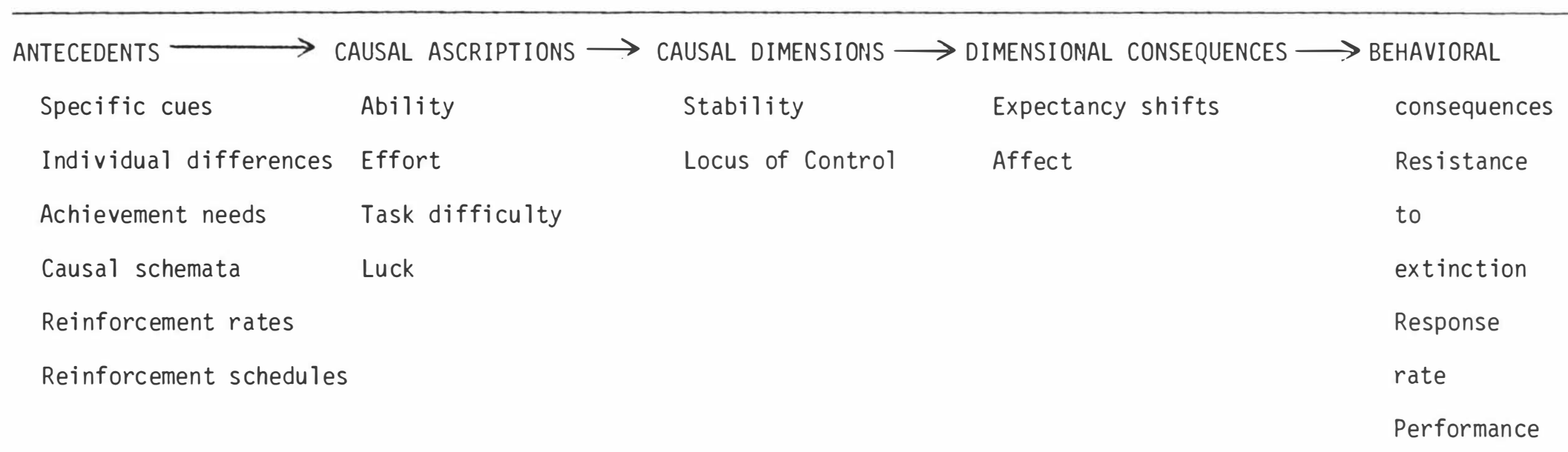


Veroff, Atkinson, Field, \& Gurin, 1960). Using the Thematic Apperception Test, Veroff et. al. found fewer high scores on need for achievement with the elderly. Smith (1970), using a quick measure of achievement motivation developed from the TAT, found only slightly lower average need achievement scores among older British subjects.

While these reported age differences in need for achievement are not great, Atkindon's (1958) model of achievement motivation states that estimated ability can interact with either need to achieve or fearfulness of failure to determine aspiration level. Therefore either a low need for achievement or a high fear of failure could produce the same effect. Success and failures do not act as reinforcers for these individuals. It has been found that fear of failure or cautiousness does exist in older individuals during testing situations (Birkhill \& Schaie, 1975; Okum \& Devista, 1978). Although both low need for achievement and high fear of failure result in reduced reinforcement value (Atkinson, 1958), and lower aspiration level it should be determined if they both lead to the same attributions to failure. If so then it may be considered a possible antecedent to learned helplessness. Fear of failure (Birkhill \& Schaie, 1975) for older subjects as well as need for achievement (Weiner \& Sierad, 1974) in male college students has been shown to affect outcome in cognitive measures. Again the obvious suggestion is that intellectual assessment of the elderly should include measures of fear of failure and/or need for achievement. This is especially important within the 
contextualistic model presented. The situational plasticity of intellectual functioning could be in part due to this extraneous ability-related variable and superfluously lower scores. An appropriate measure of this variable is the Revised and Condensed Achievement Scales (Mehrabian, 1968, 1969). This test is a selfreport inventory based on Atkinson's $(1957,1964)$ conception of achievement motivation and contain measures of the motive to succeed $\left(M_{s}\right)$ and the motive to avoid failure $\left(M_{f}\right)$. The measure of achievement tendency is a result of the motive to succeed minus the motive to avoid failure $\left(M_{S}-M_{f}\right)$. The study to be proposed will investigate the relationship between the need to achieve, the fear of failure, the attributional cause to failure, and the resultant scores of intelligence.

One last variable will be investigated as a possible antecedent that might differentially by age affect causal ascriptions in an intellectual testing situation. It was stated previously that the perceived importance of outcome has an effect on the degree of learned helplessness observed. Roth and Kubal (1975) found that a high degree of importance, as well as the amount of noncontingent outcome experienced increased the likelihood of helplessness found. Importance was manipulated by presenting the failure task as either a good predictor of academic success in college, important group or as merely a puzzle, unimportant group. This finding is in agreement with the attributional reformulation of learned helplessness which would predict that the more important an outcome is in an uncontrollable situation the more helplessness is experienced. The 
resultant behavior is an inappropriate generalization and subsequent learning and responding deficits in cognitive functioning. If importance of outcome is a key variable in learned helplessness, then measures of meaningfulness or importance placed on results should be included in tests of intelligence. If a particular age group or individual has placed a high degree of importance to failure or perceived failure and also ascribe this failure to his or her lack of ability then the subsequent scores may be superfluously lower due to the effect of learned helplessness in the testing situation.

If the attributional model of learned helplessness is combined with the attributional model of achievement motivation many possible antecedents to causal ascriptions are possible. The focus here was to isolate variables that may vary for different age groups and that may also occur in a testing context. The similarity between learned helplessness and attributions to success and failure in terms of antecedents, causal ascriptions, causal dimensions and both dimensional and behavioral consequences are such that they should be combined. When this is done predictions concerning the effect of learned helplessness on intellectual functioning can be made. This therefore justifies learned helplessness as a contextualistic influence on intelligence measures.

\section{Purpose of Study}

Individuals, young or old, do not enter into a cognitive assessment situation free of factors that may systematically 
influence the results. These factors become important when they are extraneous to the definition of intelligence and when they differentially restrict or reduce cognitive measures for identifiable groups of people. The purpose of this study was to propose that age differences in attributions to failure was one such factor, and that it had the potential of differentially restricting or reducing cognitive measures in the elderly.

Research findings using the reformulated model of learned helplessness indicated that inappropriate generalizations develop from a real or perceived uncontrollable situation that was, in fact, controllable. The inappropriate generalizations are moderated by causal attributions made by the individual to account for the performance. Attributions to one's ability in a failure situation has been found to be related to deficits in cognitive measures while attributions to one's effort are related to improvement in scores.

It was proposed that elderly persons in a testing situation were more likely to attribute test failure to their own lack of ability while younger subjects attributed the same failure to a lack of effort. It was also proposed that these attributional differences between age categories would relate to differences in cognitive measures that differentially lower elderly persons' scores.

The present investigation was designed to compare the effects of manipulated and nonmanipulated attributions to response independent failure between two age categories. Specifically, the effect of manipulating cause (i.e. lack of effort or lack of ability) to response- 
independent-failure and its relationship to dependent measures of causal attributions and cognitive scores, in younger and older persons, were investigated. The same measures were assessed in groups that experience the same response-independentfailure but with no explanation offered by the experimenter as to the cause of the failure and in a group that was not given any information concerning outcome. The latter two groups when compared to the manipulated groups, was used to assess age differences in cognitive measures and attributions to failure. The latter two groups when compared to each other, were used to assess the difference between failure feedback from the experimenter and failure feedback from the test alone. The implication was that if the two nonmanipulated attribution groups were similar in dependent measures then failure feedback from a test alone was sufficient to produce the effects found. The reformulated model of learned helplessness predicted that deficits in cognitive functioning occur when individuals receiving noncontingent failure attribute the failure to their ability. Attributions of effort to the noncontingent failure do not show deficits but rather improvement in scores. Based on that premise, subjects in the nonmanipulated attribution groups were expected to exhibit high scores on cognitive measures if they attributed the noncontingent failure to effort, much like a failure-effort-group. Also subjects in the nonmanipulated groups were expected to exhibit low cognitive scores if they attributed the failure to their ability, much like a failureability-group. 


\section{Hypotheses}

The following hypotheses were tested.

1) It was hypothesized that elderly subjects about to be tested, would expect to perform poorly and this poor performance would be attributed to internal, stable conditions while younger subjects would expect to perform well and attribute performance to their effort. Indirect support for this hypotheses was provided by Schulz (1976, 1979), Okun (1976), and Weiner (1974).

2) It was hypothesized that age differences would be found in the degree to which effort and ability were perceived as cause for failure. Support for this was suggested by Kukla (1972), Ruppucci (1975), Weiner \& Kukla (1970), and Weiner \& Sierad (1975).

3) It was hypothesized that differences in cognitive measures would be found between manipulated and nonmanipulated attribution groups given noncontingent failure and that these differences between groups would not be the same for both age categories. Cognitive measures for subjects in manipulated attributions to failure were predicted to be high for the effort-manipulated-group and low for the ability-manipulated-group in both age categories. It was hypothesized that elderly subjects in the nonmanipulated attribution to failure groups would exhibit lower cognitive scores than the elderly manipulated attribution of effort to failure group. Younger subjects in the nonmanipulated attribution to failure groups were hypothesized to show higher cognitive scores than the younger manipulated attribution of ability to failure group. Support for this comes from the learned helplessness literature 
involving cognitive measures (Dweck, 1975; Dweck \& Reppucci, 1973; Wortman, Panciera, Shusterman \& Hibscher, 1976). Added support can be found in Weiner (1974). 


\section{Method}

\section{Subjects}

One hundred females, all of whom were paid five dollars (\$5) volunteered to participate in the study. Fifty older participants ( $\bar{x}$ age 66.8 ) were recruited from community centers in the Richmond metropolitan area, while the younger volunteer population $(\bar{x}$ age 20.7 years) was drawn from a large urban university. All subjects were told beforehand that they would be given measures of intelligence along with questionnaires on how they performed and why. All subjects were briefed as to the procedure and required to sign a consent form (See Appendix A). No one refused to participate. Materials

All testing materials and questionnaires were contained in bound $81 / 2^{\prime \prime}$ by $11 "$ booklets. Need for Achievement Scales

The Mehrabian Measures of Achieving Tendency (Mehrabian and Bank, 1978) consisted of thirty eight statements (see Appendix B). Subjects were asked to indicate the degree to which they agreed or disagreed with the statement on a nine-point scale from very strong agreement to very strong disagreement.

\section{Synthetic Test}

This bogus test, labeled Synthetic, consisted of thirty series of digits varying in length (see Appendix C). Subjects were told to look for a pattern in each series and determine what the next digit would be. Only four of the thirty series had a discernable pattern, while the other twenty-six series consisted of random numbers. 
This was to assure equal failure for all groups and ages. The test had an announced time limit of six minutes.

Reasoning Test

This test, labeled Reasoning (Thurstone and Thurstone, 1950: S.R.A. Primary Mental Abilities), consisted of thirty series of letters (see Appendix D). Subjects were required to look for a pattern in each series and determine what the next letter would be. There was a test time limit of six minutes.

Hidden Patterns Test

This test (Thurstone, 1962: Educational Testing Service) consisted of two hundred figure patterns (see Appendix E). Using a model pattern in the upper right corner of the test, subjects were required to determine which of the two hundred figure patterns contained the model pattern and to place an $X$ in the space below each pattern in which the model appeared. The time limit for this test was two minutes.

Paper Folding Test

In the Paper Folding Test (Thurstone, 1962: Educational Testing Service), the individual was to imagine folding and unfolding square pieces of paper (see Appendix F). In each of the ten problems there were figures to the right and left of a dividing line. The figures on the left represented a square piece of paper being folded, the last of which had one or two small circles drawn to show where holes had been punched. The figures to the right represented five possible views if the 
figure was unfolded. Subjects were required to decide which one of the five figures was the correct view and draw an $x$ through that figure. There was a three minute time limit for this test. A page of sample problems was given before all tests to assure the subject's knowledge of the procedure.

\section{Attribution Questionnaires}

Repeated measures of subject's causal attributions to test performance were assessed at three occasions: before testing, immediately following the first test, and following completion of a test battery. Pre-Test Attribution Questionnaire

This questionnaire consisted of ten items measuring one's typical performance on measures of intelligence, expectations of success, one's perceived intelligence, and attributions of causality to effort, ability, task difficulty, and luck (see Appendix G). All item options were based on a ten point scale from one to ten. Subjects were asked to respond to each item by placing an $X$ somewhere on the ten point scale. Attribution items were worded to refer to the test subjects were about to attempt .

\section{Post-Failure Attribution Questionnaire}

This questionnaire consisted of twelve items similar to the attribution questionnaire given before testing (see Appendix $\mathrm{H}$ ). However, the attribution items were worded to refer to the test subjects just completed. The questionnaire also inquired if the results were worse or better than they expected, 
whether it was a success or failure, and level of expectations of success for subsequent tests.

\section{Final Attribution Questionnaire}

This was the same questionnaire as the Post-Failure Attribution Questionnaire with two exceptions (see Appendix I). The $i$ tems were worded to refer to a battery of tests all subjects just completed. Also the expectations of future performance was worded to refer to future tests in general.

Procedure

Each female subject met individually by the experimenter who briefed her as to the procedure. The following instructions were given during briefing:

The purpose of this study is to investigate and develop information concerning testing. This will require you to give us your opinion on various matters and to take a few short tests. At any time between sections of this session you may take a break if you like. You have the right to withdraw from continuing at any time during the session. All the information collected will be kept strictly confidential. Further instructions will be given later but before we begin, do you have any general questions?

All subjects were first given the Mehrabian Measure of Achieving Tendency. The experimenter worked with them for the first two or three statements to assure proper knowledge of the scale. All subjects were then given the pre-test attribution questionnaire. Upon completion of preliminary measures and prior to testing, the subject was assigned to one of five experimental or control groups. Subjects in the five groups were varied in the type of information concerning the test they were about to attempt and whether or not they would experience noncontingent failure. The complete design is presented in Figure 2. 
Research Design

\begin{tabular}{|c|c|c|c|}
\hline $\begin{array}{l}\text { Pre-Test } \\
\text { Attribution }\end{array}$ & $\begin{array}{c}\text { Exposure To } \\
\text { Non-Contingent }\end{array}$ & $\begin{array}{l}\text { Failure } \\
\text { Feedback }\end{array}$ & Post Measures \\
\hline
\end{tabular}

\begin{tabular}{ll}
\hline Condition 1 & $\begin{array}{l}\text { Informed that test } \\
\text { will be a measure } \\
\text { of Abilitity }\end{array}$ \\
& \\
Condition 2 & $\begin{array}{l}\text { Informed that test } \\
\text { will be a measure } \\
\text { of Effort }\end{array}$ \\
\end{tabular}

of Effort

Condition 3

Failure-No-

Reason-Given

Condition 4

Failure-No-

Feedback

Condition 5

Control
No causal ascriptions given

No causal ascriptions given

No causal ascriptions given
Took synthetic test

in which most problems were Non-soluable

Took synthetic test in which most problems were Non-soluable

Took synthetic test in which most problems were Non-soluable

Took synthetic test in which most problems were Non-soluable

Did not take synthetic test
Told that test performance was a Took intelligence failure

Told that test performance was a test subtes ts Took intelligence failure

Told that test performance was a failure

Took intelligence test subtests

Not told anything Took intelligence. test subtes ts

Took intelligence test subtes ts 
Prior Test Information

Prior information concerning the test was intended to manipulate causal outcomes attributed to test results. The intended manipulations to causal outcomes were: Failure ability, the outcome of the task was due to the subject's ability; failure effort, the outcome of the task was due to the amount of effort they expand; failure no-reason given, failure no-feedback and control subjects were not given any causal ascription information from the experimenter. Pre-test instructions by condition are presented below (adapted from Kukla, 1972, p. 171):

Condition 1: Failure Ability

The reason we're interested in this task is that we've found it to be a very pure measure of ability to organize material into patterns. It's pure, in the sense that it's relatively unaffected by effort. Some people just seem to have the correct number leap up at them, while others don't. And, within the time limit set, whether a person works very hard or takes it easy makes little difference in her score. This makes the task especially wellsuited to studying the relation between personality factors and ability factors.

Condition 2: Failure Effort

The reason we're interested in this task is that we've found that success in such organization of material into patterns is heavily influenced by the amount of effort a person puts into the task, that is, the motivation she has to do well. Even people with high ability for this kind of task do rather poorly if they do not give their full attention to searching for numbers, while people with somewhat lower ability can do quite well if they just search hard enough. For this reason, it's possible to use the task to determine which conditions lead to greater motivation among people.

Condition 3: Failure No-Reason-Given; 4: Failure-No Feedback; 5: Control

No manipulation of attributions were given. 


\section{Exposure to Noncontingent Failure}

Conditions one, two, three, and four were given the Synthetic test. Upon completion of this noncontingent failure test, the failure ability, failure effort and failure no-reason given subjects received feedback from the experimenter stating that she was correct on about 25 percent of the test and that was considered not very good. They were also told that they would be given the correct answers later but for now asked to continue. Individuals in the failure no-feedback condition were not told anything after completion of the Synthetic test. Subjects in the four failure conditions were then given the post-failure attribution questionnaire. Post Measures and Debriefing

Following attributional and failure manipulations all conditions including the control subjects were tested on the three intelligence subtests; reasoning, hidden patterns, and paper folding. The final attribution questionnaire was then given.

The experimenter announced that the session was over and that if a subject wished to go back and finish a test they could. They were then reminded of the four tests (three tests for the control condition) and asked which one or ones they would like to go back to.

At this point another experimenter came into the room while the first experimenter left. This second experimenter then fully debriefed each subject and probed for suspicion concerning the perceived authenticity of the bogus (synthetic) test. Care was taken to assure each individual understood that the manipulation 
of failure was independent of their behavior and that the results

did not reflect intelligence. Once the experimenter was convinced

that the individual was aware of the false feedback, release of

information and payment forms were given to sign (see Appendix J).

Summary Condition Interventions

Summary of prior test information and exposure to noncontingent

failure are as follows:

Condition 1: Failure Exposure Followed By "Failure Due To Ability" Feedback

The subject was told the test they were about to take was a measure of their ability, experienced the noncontingent failure test, told they had failed, given the post-failure attribution questionnaire and three intelligence subtests.

Condition 2: Failure Exposure Followed By "Failure Due To Effort" Feedback

The subject was told the test they were about to take was a measure of their effort, experienced the noncontingent failure test, told they had failed, given the post failure attribution questionnaire, and three intelligence subtests.

Condition 3: Failure Exposure Followed By Failure Feedback With No Reference To Effort Or Ability As Cause

The subject experienced the noncontingent failure test, told they had failed, given the post failure attribution questionnaire, and three intelligence subtests.

Condition 4: Failure Exposure; No Failure Information

The subject experienced the noncontingent failure test, not given any outcome information by the experimenter, given the post failure attribution questionnaire, and three intelligence subtests.

\section{Condition 5: Control No Failure Exposure}

The subject was not given the noncontingent failure test or the post failure attribution questionnaire.

The subject was given the three intelligence subtests. 
Analyses

Cognitive measures: Subjects in all five conditions and both age categories were administered three intelligence subtests (Reasoning, Hidden Patterns, and Paper Folding Tests). Hypothesized differences by age and condition in these measures were tested using an analysis of variance and linear contrast procedures.

Causal attributions: Age differences in attributions to test results-prior-to-testing were assessed using an analysis of variance procedure on pre-test attribution measures. Age by condition differences in attributions of effort and ability to test failure was tested using a linear contrast procedure on results from the ability and effort items in the post-failure attribution questionnaire. Other items in the post failure attribution questionnaire were assessed using an analysis of variance procedure. 
Results

Manipulation Checks

Pre-Test Attribution Manipulation. Two of the four failure groups were informed that the test they were about to take was a pure measure of either their ability (failure ability group) or their effort (failure effort group). In order to assess the effectiveness of the ability versus effort manipulation in these two groups, subjects were asked effort and ability causal ascriptions to failure after the Synthetic test. A 2 (age) by 2 (failure ability, failure effort group) analysis of variance was conducted on the ability and effort items from the postfailure attribution questionnaire. (This measure of attribution manipulation was not a pure measure of the effectiveness of the manipulation due to possible causal attributions developed after failure independently of pre-test information. This will be addressed in the discussion section.) The 2 (age) by 2 (ability, effort manipulation) analys is of variance in Table 1 showed differences in the effort attribution item for condition $(p<.05)$ but not age or the interaction of age by condition. No significant differences were found in the ability item. Table 2 lists the mean scores to the effort item for both age categories by condition. Subjects in the effort manipulation group for both ages were higher than the ability group. Subjects in the effort manipulation group for both ages, attributed more effort to the outcome than subjects in the ability manipulated group.

Failure Manipulation. Twenty-six of the thirty problems in the fictitious first test were actually random 
Table la

Results of the Age by Condition

Analysis of Variance to Question:

"To What Extent Did Your Effort Play a Part In The Outcome?"

\begin{tabular}{|c|c|c|c|c|}
\hline Source & ss & $d f$ & $\mathrm{~ms}$ & $f$ \\
\hline Total & 341.90 & 39 & & \\
\hline Condition & 48.4 & 1 & 48.4 & $6.03^{\star}$ \\
\hline Age & 3.6 & 1 & 3.6 & .45 \\
\hline Age $x$ Condition & .9 & 1 & .9 & .11 \\
\hline Error & 289.0 & 36 & 8.02 & \\
\hline
\end{tabular}


Table lb

Results of the Age by Condition

Analys is of Variance to Question:

"To What Extent Did Your Intellectual Ability Play a Part In The Outcome?"

\begin{tabular}{lrrrr}
\hline & & & & \\
\hline Source & ss & df & $\mathrm{ms}$ & $f$ \\
\hline Total & 340.77 & 39 & & \\
Condition & 11.02 & 1 & 11.02 & 1.22 \\
Age & 3.02 & 1 & 3.02 & .33 \\
Age $\times$ Condition & .22 & 1 & .22 & .02 \\
Error & 340.77 & 36 & 9.06 & \\
\hline
\end{tabular}




\section{Table 2}

Means to Effort Item After Failure for Ability And Effort Manipulated Groups

$$
\begin{aligned}
1 & =\text { Low Effort Attribution } \\
10 & =\text { High Error Attribution }
\end{aligned}
$$

$\begin{array}{lcc} & \text { Young } & 01 d \\ \text { Ability Manipulated Group } & 4.7 & 5.0 \\ \text { Effort Manipulated Group } & 6.6 & 7.5\end{array}$


numbers with no correct answers. The test was constructed to be credible and yet assure equal failure for both age groups, under al conditions.

The first question on the post-failure attribution questionnaire required subjects to evaluate their performance on a ten-point scale from 1 (extreme failure) to 10 (extreme success). Since al1 four failure groups received the failure test, no appropriate comparative analysis could be conducted to directly test the failure maripulation. However, the analysis of variance in Table 3, indicated that no significant differences in perceived failure were found for age, condition or the interaction. All mean scores to this item by age and condition were between 1.6 and 2.6 indicating that subjects in all four failure conditions and both age categories perceived the test results as indicating failure.

Hypothesis I: Attributions After Failure

As stated previously, subjects were asked to respond to an attribution questionnaire prior to testing and experimental manipulations. It was predicted that elderly subjects about to be tested would expect to perform poorly and this poor performance would be attributed to internal, stable conditions while younger subjects would expect to perform well and attribute performance to the effort.

Pre-test age differences in expectation of success was assessed by the question: "How well do you expect to do on the test you are about to take?" Possible responses ranged from 1 (very poor) to 10 (very well). An analys is of variance procedure indicated 
Table 3

Results of the Age by Condition

Analysis of Variance to Question:

"Would You Evaluate Your Score As A Success or Failure?"

\begin{tabular}{lrrrc}
\hline Source & ss & df & $\mathrm{ms}$ & $f$ \\
\hline Total & 115.55 & $7 \underline{9}$ & & \\
Condition & 3.25 & 3 & 1 & .72 \\
Age & .05 & 1 & .05 & .03 \\
Age x Condition & 4.05 & 3 & 1.35 & .90 \\
Error & 108.2 & 72 & 1.50 & \\
\hline
\end{tabular}


significant age differences in response to this item $(F=16.41$, $p<.01)$. The means were in the predicted direction with the mean young response to this item being 7.0 while the older group mean was 5.9.

An analysis of variance was conducted using the causal attributions of ability, effort, task difficulty, and luck to expected results as dependent measures. Table 4 contains the pretest attribution questionnaire items, the means for each age category and the level of significance for each item. Significant differences by age were found in three attribution questions concerning expected test performance; luck $(p<.05)$, test difficulty $(p<.01)$, and effort $(p<.01)$ items. Mean results of these items were in the predicted direction. Elderly subjects compared to younger subjects were likely to attribute their test performance less of ten to luck and effort and more often to task difficulty (see Table 4). Age Differences in Other Pre-Test Measures

Responses on other items in the pre-test attribution questionnaire and the Mehrabian Measures of Achieving Tendency which no predictions were made were also assessed. An analys is of variance was conducted between the two age categories using responses to the remaining pre-test questionnaire items and total achievement need scores as dependent measures. As indicated by the results in Table 4, significant age differences were found in the importance to do well item $(p<.05)$. Evaluation of the mean response to this item by age indicated that younger subjects felt it was more important to do well in the task, 
Table 4

Results of AiNOVA on Age Differences to the Ten Items on the Post-Failure Attribution Questionnaire

1. How well do you expect to do on the test you are about to take?

$F=16.41 \quad P<.001 \quad 1=$ very poor 10 very well $\bar{x}$ young $=7.0 \quad \bar{x}$ old $=5.7$

2. Do you think your intellectual ability will have much of an influence on your test performance?

$\underline{F}=.01 \quad p<. \underline{9} 2 \quad 1=$ no influence $10=$ total influence $\bar{x}$ young $=6.3 \quad \bar{x}$ old $=6.3$

3. Do you think luck will have riuch of an influence on your test performance?

$\underline{F}=4.0 E \quad P<. \underline{0} 4 \quad I=$ no influence $10=$ totally luck $\bar{x}$ young $=3.6 \quad \bar{x}$ old $=3.6$

4. Do you think the difficulty of the test will have much of an influence on your test performance?

$F=24.47 \quad P<.0001 \quad 1=$ none $10=$ total $\bar{x}$ young $=7.4 \quad \bar{x}$ old $=5.4$

5. Do you think the effort you put into taking the test will have much of an influence on your test performance? $F=13.66 \quad p<.0004 \quad 7=$ none $10=$ total $\bar{x}$ young $=7.7 \quad \bar{x}$ old $=6.3$

6. In general how well do you perform on written tests? $\mathrm{F}=18.32 \mathrm{p}<.001 \quad \mathrm{l}=\mathrm{very}$ poor $10=$ very well $\bar{x}$ young $=7.6 \quad \bar{x}$ old $=6.2$

7. Recently my intellectual abilities $\mathrm{F}=49.06 \quad \mathrm{P}<.0001 \quad \mathrm{~T}$ =show improvement 10 = show deterioration $\bar{x}$ young $=3.6 \quad \bar{x}$ old $=5.9$

8. How important is it to you to do well on the test? $\underline{F}=5.53 \quad \mathrm{P}<. \underline{\mathrm{O}} 2 \quad 1=$ not important $10=$ very important $\bar{x}$ young $=7.8 \quad \bar{x}$ old $=6.8$ 
Table 4 (continued)

9. How important is it not to fail this test?

$\mathrm{F}=1.17 \quad \mathrm{p}<. \underline{28} \quad 1=$ no importance $\quad 10=$ very important $\bar{x}$ young $=7.2 \quad \bar{x}$ old $=6.6$

10. Do you think your age will have much of an influence on your test performance?

$\mathrm{F}=.01 \quad \mathrm{p}<.93 \quad 1=$ nothing $10=$ totally determine $\bar{x}$ young $=5.42 \quad \bar{x}$ old $=5.46$ 
than the oider subjects. The filovif in Tatle 5 indicates

significant age differences in the need for achievement measures. The means for the Mehrabian Measures of Achieving Tendency Were 69.44 for the young group and 22.63 for the clder group. The higher the score the higher the need for achievement. Using the measure, younger subjects report a significantly higher need for achievement than older subjects.

Hypothesis II: Attributions to Effort and Ability After Failure It was predicted that age differences would be found in the degree to which effort and ability were perceived as cause for failure. Responses to effort and ability questions given to the four failure conditions after the failure test were used to assess these differences. Elderly subjects were expected to attribute less of the outcome to their own lack of effort than their own lack of atility while younger subjects were predicted to attribute more of the outcome to their own lack of effort than their own lack. of ability. In terms of attributions by group, the above predictions meant that the two elderiy non-manipulated attribution groups (failure no-reason given and failure no-feedback) would attritute the failure much like the failure ability group and differ significantly from the elderly failure effort group. Alternatively. the younger failure no-reason given group and failure no-feedback group were predicted to attribute the failure much like the young failure effort group and differ significantly from the young failure ability group. Due to the specific predictions between the four failure groups in each category, a linear contrast design was used to test the hypotheses. 
Table 5

ANOVA Age Differences in Need for Achievement

\begin{tabular}{lrrrr}
\hline Source & ss & df & $m s$ & $f$ \\
\hline Total & 1011894.51 & 99 & & \\
Age & 30171.69 & 1 & 30171.69 & $41.23^{\star \star}$ \\
Error & 71722.89 & 98 & 731.86 & \\
\hline
\end{tabular}

${ }^{\star \star} p<.01$ 
Table 6 lists the overall level of significance for the failure groups (cross-age comparisons), the level of significance for the linear contrasts within age, and the predicted relations between the four failure groups for the ability and effort items. In reference to the effort question, older subjects in the two non-manipulated attribution groups were comparable to the failure ability group $(p<1.0)$ and differed significantly from the older failure effort group $(p<.01)$ as predicted. The essential linear contrast for the younger subjects was the average of the two non-manipulated attribution groups versus the failure ability group. Non-significant differences were found in this linear contrast $(p<.43)$.

Evaluation of the means for older subjects by condition in response to the effort item were in the predicted directions. The higher the mean score the more effort attributed to the failure outcome. Group 3 (5.3), 4 (4.7), and 1 (5.0) were significantly lower than group $2(7.5)$ as predicted.

Analysis of the ability item within each age category were not significant thus not supportive of the hypotheses for either age.

\section{Other Attributions and Expectations After Failure}

A total of ten other questions in the post failure attribution questionnaire were given after the failure test (see Appendix $H$ ). No specific predictions were made for these ten items. A series of 2 (age category) by 4 (failure condition) analysis of variance were performed and only significant main effects or interactions 
Table 6

Within Age Linear Contrasts to Mean Responses in the Ability and Effort Attribution Questions After Failure

To What Degree Were The Results Due To Your Effort?

\begin{tabular}{|c|c|}
\hline Contrast & $f$ \\
\hline $\begin{array}{l}\text { Older Group } 3 \text { vs. Group } 4 \\
\text { Group } 3 \text { \& } 4 \text { vs. Group } 1 \\
\text { Group } 3 \text { \& } 4 \text { vs. Group } 2 \\
\text { Young Group } 3 \text { vs. Group } 4 \\
\text { Group } 3 \& 4 \text { vs. Group } 2 \\
\text { Group } 3 \& 4 \text { vs. Group } 1\end{array}$ & $\begin{array}{l}.26 \\
.00 \\
6.02 \star \star \\
1.42 \\
1.17 \\
.62\end{array}$ \\
\hline
\end{tabular}

To What Degree Were The Results Due To Your Ability

\begin{tabular}{|c|c|}
\hline Contrast & $f$ \\
\hline $\begin{array}{l}\text { Older Group } 3 \text { vs. Group } 4 \\
\text { Group } 3 \text { \& } 4 \text { vs. Group } 1 \\
\text { Group } 3 \text { \& } 4 \text { vs. Group } 2 \\
\text { Younger Group } 3 \text { vs. Group } 4 \\
\text { Group } 3 \& 4 \text { vs. Group } 2 \\
\text { Group } 3 \& 4 \text { vs. Group } 1\end{array}$ & $\begin{array}{r}2.86 \\
.00 \\
.95 \\
.54 \\
.72 \\
.01\end{array}$ \\
\hline
\end{tabular}

\footnotetext{
Group 1 = Failure Ability Group 3 = Failure No Reason Given Group 2 = Failure Effort Group 4 = Failure No Feedback
} 
were reported. Analysis revealed a significant main effect for condition in the task difficulty item; how difficult do you think this task was, ( df $3,72, F=3.86, p<.01$ ). Post hoc Tukey test analysis of means showed that only group 2 (failure effort) and group 4 (failure no-feedback) were significantly different $(p<.01)$. This significant difference indicated that subjects in the failure effort group perceived the task to be easier than the failure no-feedback group.

\section{Hypothesis III Age by Condition Cognitive Differences}

Age by condition interactions were predicted for each of the dependent variables. The three subtests (reasoning, hidden figures, and paper folding tests), were used as dependent measures to assess the effect of the experimental manipulation. Three methods of analyses were performed, linear contrasts, 2 (age) by 5 (condition) ANOVA, and 2 (age) by 4 (failure condition) ANOVA.

Linear contrasts were conducted to assess between and within age comparisons on cognitive measures. It was hypothesized that young subjects that are not given attributions or reasons for failure, will ascribe the failure to a lack of effort which will lead to an increase in performance. 01der subjects that are not given a reason for test failure will attribute the failure to a lack of ability which will lead to a decrease in test performance. As a result young subjects in groups 3 and 4 (failure no-reason given and failure no-feedback) would exhibit higher scores than young subjects in group 1 (failure ability). 01der subjects in groups 3 and 4 would show significantly lower scores on the three 
Figure 3

Age by Condition Plot of Test Scores-Reasoning

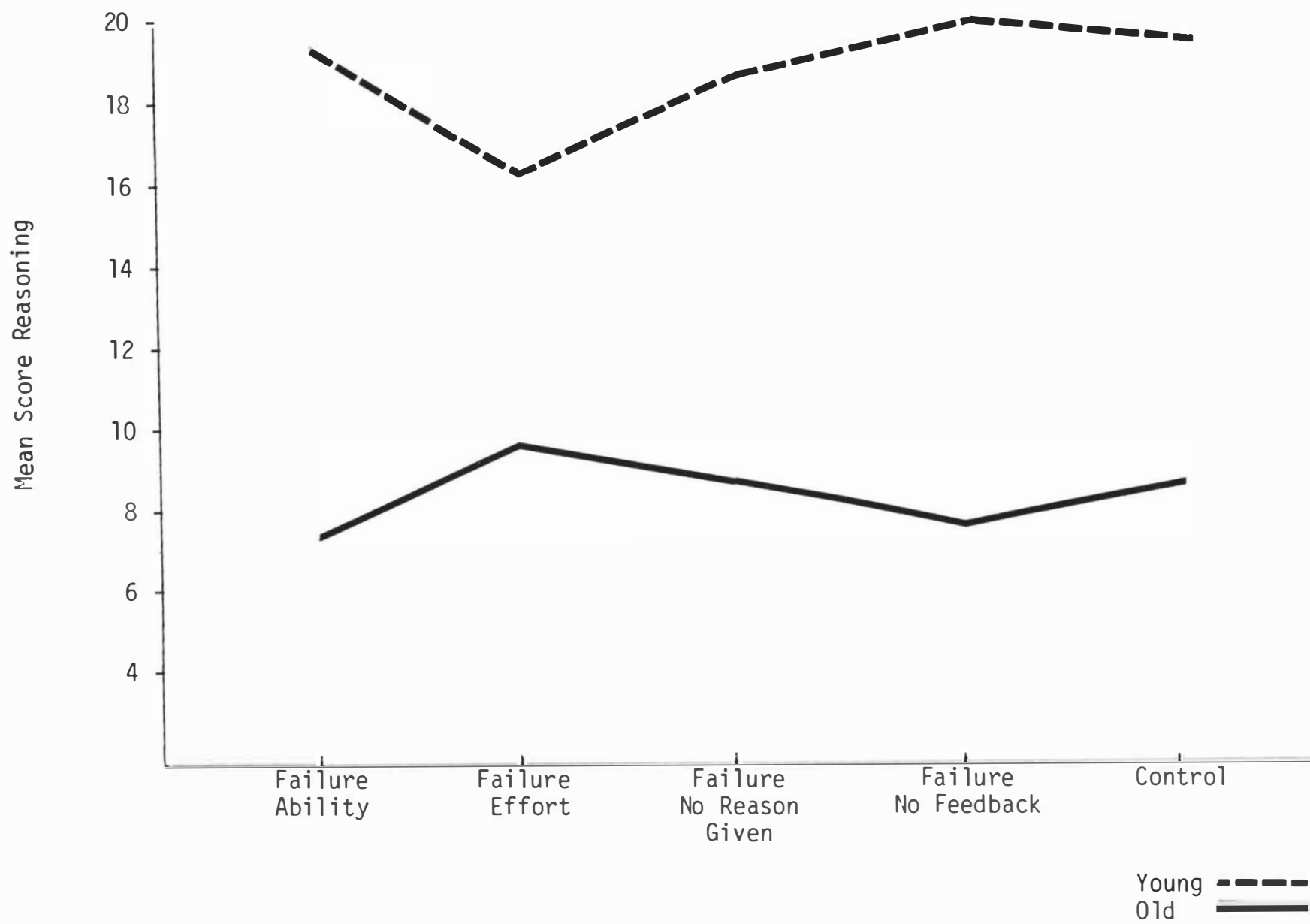


Figure 4

Age by Condition Plot of Test Scores-Hidden Patterns

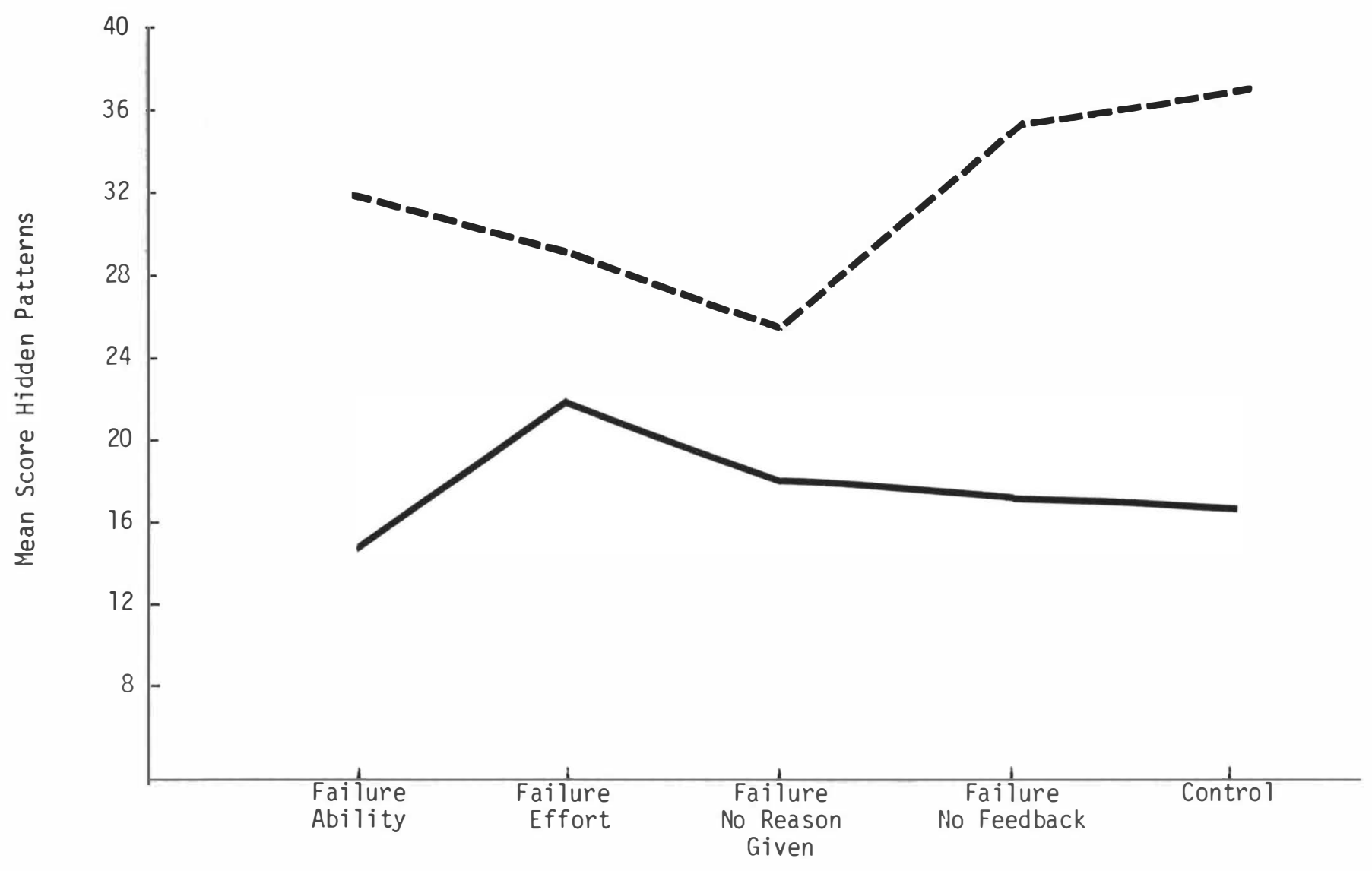

Young $1-2$

old 
Figure 5

Age by Condition Plot of Test Scores-Paper Folding

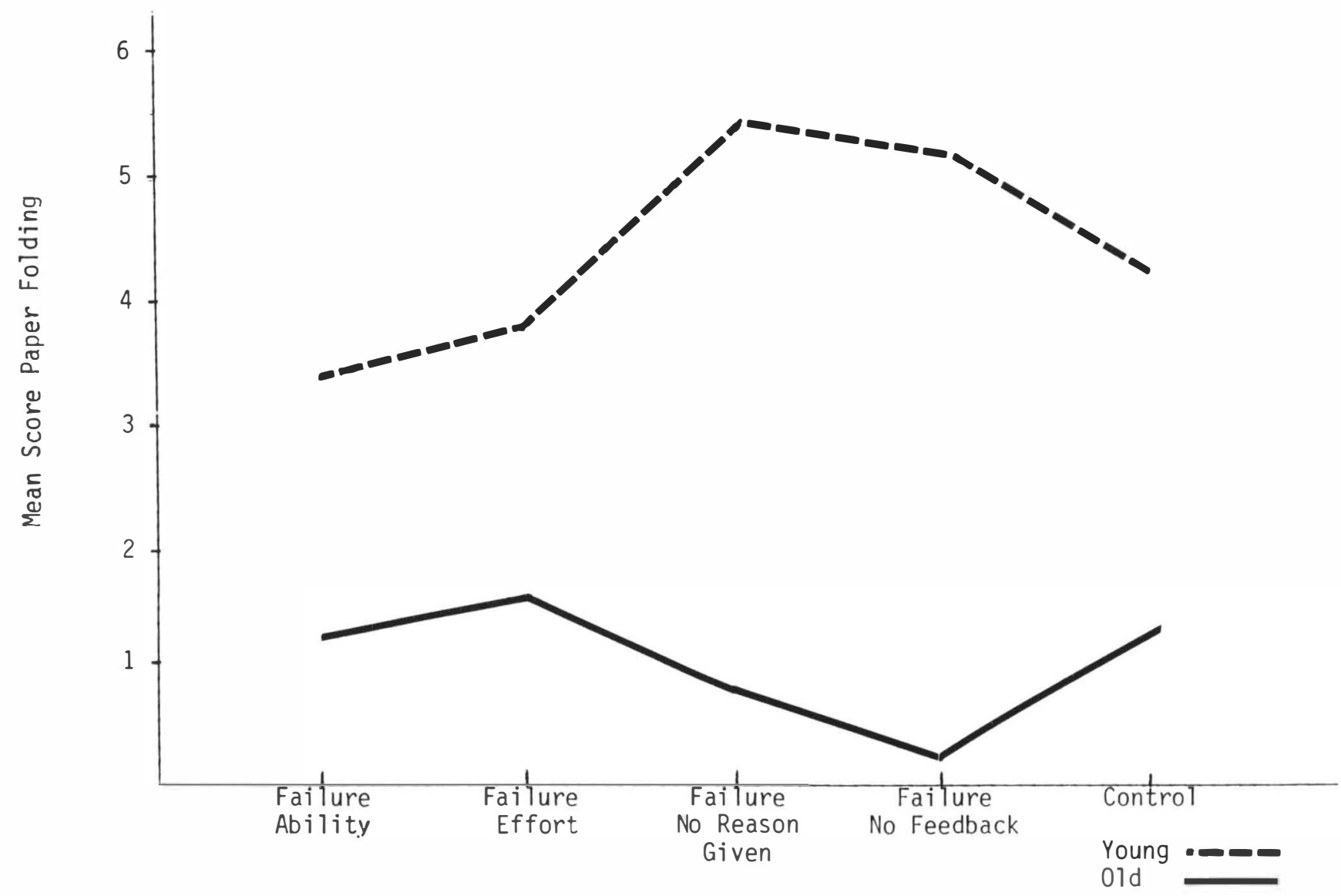


tests compared to older subjects in group 2 (failure effort). In sumary, the non-manipulated attribution failure groups (group 3 and 4) were expected to demonstrate facilitation or higher scores for younger subjects and deficits or lower scores for older subjects. Figures 3-5 illustrate the age by condition relationship for each dependent variable. Mean scores by age and condition on reasoning, hidden patterns, and paper folding tests are presented in Table 7. The individual mean contrasts within and between the age categories are shown in Table 8 . All between age contrasts except two; failure ability young contrasted with old in hidden patterns $(p<.10)$ and failure no-reason given young contrasted with old in hidden patterns $(p<.08)$ were significant. In all but these two contrasts younger subjects in each condition and each test obtained significantly higher scores. Analysis of within age linear contrasts in Table 8, showed that, of the predicted significant differences between means, only the average of failure no-reason given and failure no-feedback contrasted to the mean of failure ability group for younger subjects in the paper folding test was significant $(p<.01)$. Heans were in the predicted direction with the failure no-reason given and failure no-feedback groups scoring significantly higher on the paper folding test than the failure ability group. The contrasts of failure noreason given and failure no-feedback was to assess differences between failure feedback from a test and experimenter and failure feedback from the test alone. Significant differences were not predicted between these two groups although significant differences 
Table 7

MEAN SCORES BY AGE AND CONDITION IN THE REASONING, HIDDEN PATTERNS, AND PAPER FOLDING TESTS

$\begin{array}{ccc}\text { REASONING } & \text { HIDDEN PATTERNS } & \text { PAPER FOLDING } \\ 19.2 & 32.0 & 3.38 \\ 16.3 & 28.6 & 3.78 \\ 18.7 & 25.5 & 5.34 \\ 20.0 & 35.9 & 5.20 \\ 19.7 & 37.3 & 4.36 \\ 7.1 & & \\ 9.7 & 14.6 & 1.34 \\ 8.6 & 21.6 & 1.56 \\ 7.3 & 18.0 & 0.84 \\ 8.6 & 17.1 & 0.14 \\ & 16.9 & 1.28\end{array}$


Table 8

Between and Within Age Linear Contrasts on Mean Scores

in the Reasoning, Hidden Patterns, and Paper Folding Tests

Summary Table of $F$ Ratios

Between Age Contrasts by Group

\begin{tabular}{lccccc}
\hline Test & $\begin{array}{c}\text { Group 1 } \\
\text { Young/01d }\end{array}$ & $\begin{array}{c}\text { Group 2 } \\
\text { Young/01d }\end{array}$ & $\begin{array}{c}\text { Group 3 } \\
\text { Young/01d }\end{array}$ & $\begin{array}{c}\text { Group 4 } \\
\text { Young/01d }\end{array}$ & $\begin{array}{c}\text { Group 5 } \\
\text { Young/01d }\end{array}$ \\
\hline Reasoning & $40.18 \star \star$ & $11.95^{\star \star}$ & $27.99 \star \star$ & $44.26 \star \star$ & $33.81 \star \star$ \\
Hidden Patterns & $15.57 \star \star$ & 2.68 & 3.08 & $19.34 \star \star$ & $22.77 \star \star$ \\
Paper Folding & $4.99 \star$ & $5.91^{\star}$ & $24.28 \star \star$ & $30.70^{\star \star}$ & $11.37 \star \star$ \\
\hline
\end{tabular}

$$
\begin{aligned}
& \star_{p}<.05 \\
& \star \star p<.01 \\
& \text { df } 1,90
\end{aligned}
$$

Group 1 = Failure Ability

Group 2 = Failure Effort

Group 3 = Failure No Reason Given

Group 4 = Failure No Feedback

Group 5 = Control 
Within Age Contrasts

Young

\begin{tabular}{lccr}
\hline Test & Group 3 versus 4 & Group 3 and 4 versus 1 & Group 3 and 4 versus 2 \\
\hline $\begin{array}{lcc}\text { Reasoning } \\
\text { Hidden Patterns }\end{array}$ & $.46^{+}$ & $.01+$ & $.12+$ \\
Paper Folding & $5.92^{\star+}$ & $5.71^{\star+}$ & .40 \\
& $.02^{+}$ & 3.55 \\
\hline
\end{tabular}

old

\begin{tabular}{llrl}
\hline & & .26 & $1.12+$ \\
Reasoning & $.46+$ & .56 & $1.20+$ \\
Hidden Patterns & $.04+$ & 1.15 & $1.83+$ \\
Paper Folding & $.59+$ & & \\
\hline
\end{tabular}

${ }^{\star} p<.05$

+not expected to differ significantly

df 1,90
Group 1 = Failure Ability

Group 2 = Failure Effort

Group 3 = Failure No Reason Given

Group 4 = Failure No Feedback

Group 5 = Control 
were found between the two groups for young subjects in the hidden figures test $(p<.01)$. Age by Condition Analysis of Variance

The effect of condition and age by condition interaction for the three intelligence subtests was not assessed in the linear contrast analysis. Due to this a 2 (age) by 5 (condition) ANOVA was conducted with each of the three tests. As the results of Table 9 indicate, age differences were significant at the .0001 level for all three tests. Younger subjects consistently scored higher on all tests than older subjects. Both the condition and the age by condition interaction were nonsignificant. Age by Failure Condition Analysis of Variance

Due to multiple differences between the control subjects and the four failure groups, alternative analys is were conducted. The four failure groups in each age category experienced failure and the same number of tests (four). The control group did not experience failure or as many tests. Differential fatigue effects as well as the failure manipulation may account for differences between the failure and control groups (Furry \& Baltes, 1973). Because of the multiple differences between the control and failure groups a 2 (age) by 4 (conditions) analys is of variance was conducted using the three subtests as the dependent variables.

The 2 by 4 ANOVA for each of the three tests (reasoning, hidden patterns, and paper folding) in Table 10 demonstrate that age differences were again significant for all three subtests $(p<.0001)$. 
Table 9

Age (2) By Condition (5) Analys is of Variance On The Reasoning, Hidden Patterns, and Paper Folding Tests

Reasoning

\begin{tabular}{lrrrc}
\hline Source & ss & df & ms & $f$ \\
\hline Total & 4538.96 & 99 & & \\
Age & 2766.76 & 1 & 276.76 & $151.85^{\star \star}$ \\
Condition & 16.76 & 4 & 4.16 & .23 \\
Age x Condition & 115.64 & 4 & 28.91 & 1.59 \\
Error & 1639.8 & 90 & 18.22 & \\
& & & & \\
\hline
\end{tabular}

Hidden Patterns

\begin{tabular}{lrrrr} 
Total & 14302.0 & 99 & & \\
Age & 4952.0 & 1 & 49.52 & $54.18 \star \star$ \\
Condition & 370.51 & 4 & 92.63 & 1.01 \\
Age x Condition & 845.40 & 4 & 211.35 & 2.31 \\
Error & 8134.1 & 90 & 91.39 & \\
\hline
\end{tabular}

Paper Folding

\begin{tabular}{lrrrc}
\hline Total & 703.11 & 99 & & \\
Age & 285.61 & 1 & 285.61 & $68.49 \star \star$ \\
Condition & 5.63 & 4 & 1.15 & .34 \\
Age x Condition & 36.54 & 4 & 9.13 & 2.19 \\
Error & 375.33 & 90 & 4.17 & \\
\hline
\end{tabular}

${ }^{\star \star} \mathrm{p}<.01$ 
Table 10

Age (2) By Failure Group (4) Analys is of Variance On The Reasoning, Hidden Patterns, and Paper Folding Tests

\section{Reasoning}

\begin{tabular}{lrrrr}
\hline Source & \multicolumn{1}{c}{ ss } & df & ms & $f$ \\
& & & & \\
\hline \\
Total & 3670.49 & 79 & & \\
Age & 2152.81 & 1 & 2152.81 & $110.93^{\star \star}$ \\
Condition & 6.84 & 3 & 2.28 & .12 \\
Age $x$ Condition & 113.54 & 3 & 37.84 & 1.95 \\
Error & 1397.30 & 72 & 19.41 & \\
\hline
\end{tabular}

Hidden Patterns

$\begin{array}{lrrrc}\text { Total } & 10278.30 & 79 & & \\ \text { Age } & 3123.53 & 1 & 3123.53 & 35.11^{\star \star} \\ \text { Condition } & 244.59 & 3 & 81.53 & .92 \\ \text { Age x Condition } & 593.07 & 3 & 191.02 & 2.22 \\ \text { Error } & 6317.10 & 72 & 88.97 & \end{array}$

Paper Folding

\begin{tabular}{lrrrc}
\hline Total & 538.64 & 79 & & \\
Age & 238.74 & 1 & 238.74 & $66.49 \star \star$ \\
Condition & 5.39 & 3 & 1.79 & .50 \\
Age x Condition & 35.97 & 3 & 11.92 & $3.34 *$ \\
Error & 258.53 & 72 & 3.59 & \\
\hline
\end{tabular}

${ }_{\star \star p}^{* p}<.05$ 
A significant age by condition interaction was found in the paper folding test $(p<.05)$. (Post hoc Tukey tests were excluded due to the linear contrasts having already demonstrated significant differences between age categories for each condition in the paper folding test. It was found that every young condition group scored significantly higher on the paper folding test than older subjects in the same conditions.) However, the means for the paper folding test by age in Table 7 and category as well as Figure 5 demonstrate that the failure no-reason given and failure no-feedback groups were higher than the failure ability group for young subjects while the failure no-reason given and failure no-feedback groups were lower than the failure effort group for older subjects, supporting the hypothesis. 


\section{Discussion}

The main purpose of the present study was to investigate age differences in attributions to test results and to assess the effect these attributional differences had on cognitive measures. It was proposed that the lower scores in elderly persons' intelligence measures were due, in part, to expectations of failure and attributions to test performance brought to and developed during a testing situation. 0lder persons rather than younger were considered to be at a particular disadvantage due to differences in attributions to test performance. It was hypothesized that elderly persons given failure in a testing situation would attribute the failure to a lack of their ability and subsequent cognitive measures would be lower than otherwise expected. Younger persons given the same failure would attribute the failure to a lack of their effort and subsequent cognitive measures would be lower than otherwise expected.

Justification for the above statement was a result of combining the research areas of achievement motivation and attribution theory as proposed by Weiner et. al. (1971, 1974, 1975) and the reformulated model of learned helplessness (Miller \& Norman, 1978; Abramson, Seligman \& Teasdale, 1978).

It was predicted in the first hypotheses that age differences in expectation of success and attributions to expected performance 
would be found. Significant age differences in pre-test measures were found in reported general performance on written tests, change in intellectual abilities, expectation of success, attributed cause of results to luck, test difficulty, and effort, importance of task and need for achievement.

The comparison of means revealed that older subjectes reported they generally perform poor on tests and have noticed some deterioration in their intellectual abilities while younger subjects reported better performance and an improvement in intellectual abilities. Significantly lower expectations for success were found in the elderly also.

Pre-test differences in attributions to expected test outcome revealed that elderly subjects were more likely to attribute less luck, less effort, and more task difficulty as the cause for test performance than younger subjects. According to Heiner's model of attributions to test results, luck is considered an externalvariable attribution, effort is an internal-variable attribution and task difficulty is an external-stable attribution. Significant differences in the luck and task difficulty item were not expected. While both attributions were external, younger subjects attributed influences to the unstable attribution of luck while older subjects attributed more influence to the stable attribution of task difficulty. The reformulated model of learned helplessness stated that persons who made stable attributions to noncontingent behavior were more susceptible to learned helplessness. The significant differences between age groups in the effort item were 
expected and supported the assumption that younger subjects perceived the internal-unstable attribution of effort as influencing their test performance more so than older subjects. Though age differences for the ability question were predicted, none were found. During debriefing, subjects were asked why they responded the way they did to particular attribution items. 0lder subjects frequently interpreted the term "influence your performance" both positively and negatively. An older person thatthought she would do poorly on the upcoming test could rate this item low and mean that because of her lack of ability, it would have no influence on the test or she could rate this item high and mean that her lack of ability would influence her scores but negatively. One possible reason for the unexpected nonsignificant age differences in the ability item could be this differential interpretation as observed during debriefing. Attribution questionnaires used in future research with the elderly should be worded to reduce multiple interpretations, even if the questionnaire has been used successfully with younger subjects previously.

Results from previous research findings have suggested that many of the differences found between the two age categories in the first hypotheses are related to cognitive performance (Weiner, 1974; Dweck, 1975; Dweck \& Reppucci, 1973). It was found that when placed in a helplessness learning situation, children who took personal responsibility for the outcome of their actions and attributed success and failure to presence or absence of their ability rather than effort, showed the largest performance decrements 
(Dweck \& Reppucci 1973). The findings in this hypotheses suggested older subjects exhibited some of the same attributional characteristics and expectations that resulted in perfomance decrements found in the children of Dweck and Reppucci's research (1973).

It was proposed in the second hypotheses that age differences would be found in the degree to which effort and ability were perceived as cause for failure. It was hypothesized that elderly subjects experiencing failure would attribute a higher degree of that failure to ability rather than effort. Younger subjects experiencing the same failure would attribute a high degree of the failure to a lack of effort rather than ability. Analysis of results indicated no support for this hypotheses. Only the analysis of the elderly responses for the effort item supported the hypotheses. Also, younger group means for the effort item were in the correct directions but not significantly so. Responses to the ability item did not appear to support the hypotheses for either age category. Analysis between the age categories in the two nonmanipulated attribution to failure groups revealed nonsignificant differences in the ability and effort items.

It is possible that nonsignificant differences in ability attributions by age was a result of true nonsignificant differences between the age categories. However the effort item analysis did support the hypotheses in part. Also the multiple interpretations problem found in the pre-test ability item may also be a problem in the ability item given after failure. Another problem with the attribution questionnaire used in this investigation was that 
the attribution items often contained two dimensions considered orthogonal to each other. For example, if significant age differencen were found in attributions to task difficulty, predictions concerning learned helplessness effects would be difficult to make since task difficulty is an external and stable attribution. The learned helplessness model predicted helplessness when attributions were stable and does not predict helplessness when the attributions were external. Items such as "To what degree were these results stable" or "To what degree were the results personal" would reflect the attributional dimentions suggested in the reformulated model of learned helplessness (Miller \& Norman, 1978).

Another possible explanation for the results may be in the attribution manipulation and method of analysis. An analysis of age differences in attributions to noncontingent failure was assessed by contrasting subjects in nonmanipulated attribution groups with subjects in manipulated attribution to ability or effort groups. If significant differences were found between the manipulated attribution to effort group and nonmanipulated groups, it implied that subjects in the nonmanipulated groups made ability rather than effort attributions. Nonsignificant differences between the manipulated-ability group and the nonmanipulated attribution groups would add support for that position. However, it may be that significant differences between the nonmanipulated attribution groups and the manipulated attribution to effort was a result of the effort manipulation. Even if the attribution patterns had resulted in the predicted directions it would not be known if the results were due to 
true age differences or differences in the effectiveness of attribution manipulation in the two age categories. Only a direct age comparison on the effort and ability items in the two nonmanipulated attribution groups could correct this confound. This direct analysis resulted in nonsignificant differences.

The third hypotheses was the most central to this investigation. It was hypothesized that differences in cognitive measures would be found between manipulated and nonmanipulated attribution groups given noncontingent failure and that these differences between groups would not be the same for both age categories. The dependent measures, (Reasoning, Hidden Patterns, and Paper Folding Tests) were chosen due to their frequent use in cognitive assessment of the elderly and known age differences (Schaie, 1965; Horn \& Cattell, 1966). Subjects in the failure no feedback condition were exposed to testing much like a real testing situation. If significant differences in cognitive measures were found between this group and manipulated attribution group and if the failureno-feedback group showed low scores in the elderly and high scores in younger subjects, then this age by condition interaction would support the third hypotheses. Analys is of the Paper Folding Test supported this hypotheses while analysis of the Reasoning and Hidden Patterns Tests did not.

The hypotheses was supported using scores from the Paper Folding Test once the control group was excluded from the analysis. Exclusion of the control group was justified due to its inappropriateness as an adequate control. It was intended that the control wuold 
differ from the experimental group in only failure experience.

The control group also experienced one less questionnaire and test. The potential confound of fatigue and failure was possible. Furry and Baltes (1973) found that there was a fatigue effect when testing the elderly and the Reasoning Test was one of the dependent measures that showed this fatigue effect.

The interaction in the 2 (age) by 4 (failure condition) ANOVA was significant using results from the Paper Folding Test. Figure five indicated that subjects in the failure-ability group had lower scores than the failure-effort group as predicted. This was true of both ages. The important point in this figure was that the two nonmanipulated groups were lower than the failureeffort group for the elderly, and were higher than the failureability group for the younger subjects. These patterns were predicted.

A possible explanation for the nonsignificant findings in the other two tests (Reasoning and Hidden Patterns) may be in the test itself. These two tests differed from the Paper Folding Test in difficulty, the latter being more difficult. A less difficult task may reduce the effect of noncontingent failure by providing contingent success. Also, knowledge of being correct or incorrect was much easier in the first two tests but not in the Paper Folding Test. In human learned helplessness research, both the noncontingent task or test and the subsequent contingent test were tests in which correctness or incorrectness were not obvious. Future research testing learned helplessness effects in tests varying in ambiguity of correctness within the test, would suggest which 
cognitive measures may potentially be influenced by learned helplessness.

A third explanation for nonsignificant differences in the first two subtests and significant differences in the third may be found in previous research that assessed the affect of amount of helplessness training had on performance (Roth \& Kubal, 1975). It was found that initial exposure to noncontingent failure first facilated performance while continued exposure produced deficits in performance (Roth \& Kubal, 1975). This was found using a college age population and has not been replicated using an older age group. It could be that there are age differences in the amount of noncontingent failure exposure needed to produce helplessness. This is consistant with the findings in the first hypotheses. Prior to testing, older subjects displayed failure expectations and attributions to expected outcome that are characteristic of helplessness while younger subjects did not.

In summary the third and most important hypotheses was supported by the significant age by condition interaction in the Paper folding Test. Inconsistent results between this measure and the Reasoning and Hidden Patterns Test may be due to differences between the tests rather than an ineffectiveness of the manipulations. These findings were similar to other findings (Dweck, 1975; Weiner \& Sierad, 1974). In Dweck (1975) children with "naturally" occurring helplessness were taught to attribute failure to a lack of effort. This reattribution training resulted in improvements in task persistence and less helplessness than did a group treated with success only 
experiences. Weiner and Sierad (1974) found that individuals that attributed failure to a lack of effort showed higher performance on tasks than individuals that attributed failure to a lack of ability.

Conclusions that age differences in attributions to expected and actual performance exist and that these attributions moderate performance in cognitive measures were tentative. Support for age differences in attributions to expected nerformance was found in hypotheses I. The results indicated that elderly subjects enter into a testing situation with expectations and attributions much like the "naturally" occurring helplessness discussed by Dweck (1975). Past research has found that these attributions are related to performance on tests. The second hypotheses was not supported so the hypotheses that there would be age differences in attributions to noncontingent failure was left unanswered. It may be that failure in only one test was enough to produce helplessness effects in older persons but not enough in younger persons. Subjects in the attribution manipulated groups were told that the test they were about to take was a measure of either their ability or effort. It is possible that it may take more than pre-test information to induce attributions of ability or effort. Support for the third hypotheses was found but raised more questions than it answered. Causes for significant differences in the predicted direction for one test and nonsignificant fifferences in the other two dependent measures was not known. The significant interaction of age and condition on the Paper Folding Test suggested that cognitive scores could be 
influenced by situational cues and these cues influence younger and older person's scores differently. Since the manipulated attribution groups were parallel in the Paper Folding Test, the significant age by condition interaction was due to lower scores in the elderly and higher scores in the younger nonmanipulated groups, suggesting that these situational cues are particularly disadvantageous to the elderly. Generalizations from these results to elderly cognitive assessment should be cautioned. Future research should be directed to the problems raised by this investigation. Cognitive tests varying in the amount of outcome information within the test should be in a learned helplessness framework to assess which tests of intelligence would be influenced. Also, research in which the amount of failure is varied in different age groups should be conducted. Age differences in the amount of noncontingent failure exposure needed to produce performance deficits may be found. Future research involving attributions to noncontingent failure should also contain items that reflect dimensions defined in the reformulated model of learned helplessness beside attribution items such as task difficulty, luck, effort, and ability, as in Weiner's model. Attention should be directed to attribution training in the elderly rather than a pre-test attribution manipulation. Plasticity in elderly intellectual functioning was suggested by this study, maximal effect due to attributional influences would be implied in attributional training research. 
REFERENCES 
References

Abrahams, J. P. Health status as a variable in aging research. Experimental Aging Research, 1976, 2, 63-71.

Abramson, L. Y., Seligman, M. E. P., \& Teasdale, J. D. Learned helplessness in humans: Critique and reformulation. Journal of Abnormal Psychology, 1978, 87, 49-74.

Atkinson, J. W. (Ed.) The Achievement Motive in Fantasy, Action and Society. Princeton: Van Nostrand, 1958.

Atkinson, J. W. An Introduction to Motivation. New York: Van Nostrand, 1964.

Atkinson, J. W. \& Litwin, G. H. Achievement motive and test anxiety conceived as motive to approach success and motive to avoid failure. Journal of Abnormal Social Psychology, 1960, 60, 52-63.

Baltes, P. B. \& Schaie, K. W. On the plasticity of adult and gerontological intelligence: Where Horn and Donaldson fail. American Psychologist, 1976, 31, 720-725.

Baltes, P. B. \& Willis, S. L. Toward psychological theories of aging and development. In J. E. Birren \& K. W. Schaie (Eds.) Handbook on psychology of aging. New York, Reinhold-Van Nostrand, 1977.

Birkhill, W. R., and Schaie, K. W. The effect of differential reinforcement of cautiousness in intellectual performance among the elderly. Journal of Gerontology, 1975, 30, (5), 578-583.

Birren, J. C. The Psychology of Aging. Englewood Cliffs, N. J.: Prentice-Hal1, 1964.

Botwinick, J. Cautiousness in advanced age. Journal of Gerontology, $1966,21,347-353$.

Brown, I., \& Inouye, D. K. Learned helplessness through modeling: The role of perceived similarity in competence. Journal of Personality and Social Psychology, 1978, 36, (8), 900-908. 
Chaubey, N. P., Effects of age on expectancy of success and on risk-taking behavior. Journal of Personality and Social Psychology, 1974, 29, 774-778.

Doppelt, J. C., \& Wallace, W. L. Standardization of the Wechsler Adult Intelligence Scale for 01der Persons. Journal of Abnormal Social Psychology, 1955, 51, 312-330.

Dweck, C. S. The role of expectations and attributions in the alleviation of learned helplessness. Journal of Personality and Social Psychology, 1975, 31, 674-685.

Dweck, C. S., \& Reppucci, N. D. Learned helplessness and reinforcement responsibility in children. Journal of Personality and Social Psychology, 1973, 25, 109-116.

Furry, C., \& Baltes, P. B. The effect of age differences in abilityextraneous performance variables on intellectual performance in children, adults, and the elderly. Journal of Gerontology, $1973,28,13-80$.

Hanusa, B. H., \& Schulz, R. Attributional mediators of learned helplessness. Journal of Personality and Social Psychology. $1977, \underline{35},(8), \overline{602-611 .}$

Hiroto, D. S. Locus of control and learned helplessness. Journal of Experimental Psychology, 1974, 102, 187-193.

Hiroto, D. S., \& Seligman, M. C. P. Generality of learned helplessness in man. Journal of Personality and Social Psychology, 1975, $31,311-327$.

Horn, J. L. Intelligence: Why it grows, why it declines. TransAction, 1967, 4, 23-31.

Horn, J. L., \& Cattell, R. S. Refinement and test of the theory of fluid and crystallized intelligence. Journal of Educational Psychology, 1966, 57, 253-270.

Hoyer, H. J., Labouvie, G. V., \& Baltes, P. B. Modification of response speed deficits and intellectual performance in the elderly. Human Development, 1973, 16, 233-242.

Hunt, J. M. V. Intelligence and Experience. New York: Ronald, 1961. 
Jarvik, L. F., \& Cohen, D. A biobehavioral approach to intellectual changes with aging. In C. Eisdorfer \& M. P. Lawton (Eds.), The Psychology of adult development and aging, Washington, D.C.: American Psychological Association, 1973.

Klein, D. C., Fencil-Morse, E., \& Seligman, M. E. P. Learned helplessness, depression, and the attribution of failure. $\frac{\text { Journal of Personality and Social Psychology, }}{508-516 .}$.

Kuhlen, R. G., \& Johnson, G. H. Changes in goals with adult increasing age. Journal of Consulting Psychology, 1952 , $16,1-4$.

Kukla, A. Attributional determinants of achievement-related behavior. Journal of Personality and Social Psychology, $1972,21,1 \overline{66-174 .}$

Labouvie-Vief, G., \& Chandler, M. J. Cognitive development and life-span development theory: Idealistic versus contextual perspectives. In P. Boltes (Ed.) Life-Span Development, 1979.

Labouvie-Vief, G., \& Gonda, J. N. Cognitive strategy training and intellectual performance in the elderly. Journal of Gerontology, 1976, 31, 327-332.

Mehrabian, A. Male and female scales of the tendency to achieve. Educational and Psychological Measurement, 1968, 28, 493-502.

Mehrabian, A. Measures of achieving tendency. Educational and Psychological Measurement, 1969, 29, 445-451.

Miller, I. W., \& Norman, W. J. Learned helplessness in humans: $A$ review and attribution-theory model. Psychological Bulletin, 1978, 80, 310-323.

Moulton, R. W. Effects of success and failure on level of aspiration as related to achievement motives. Journal of Personality and Social Psychology, 1965, 1, $\overline{399-406}$.

Okun, M. A. Adult age and cautiousness in decision. A review of the literature. Human Development, 1976, 19, 220-233.

Okun, M. A., \& DiVesta, F. J. Cautiousness in adulthood as a function of age and instructions. Journal of Gerontology, $1976,31,571-576$. 
Overmier, J.B., \& Seligman, M. E. P. Effects of inescapable shock upon subsequent escape and avoidance learning. $\frac{\text { Journal of Comparative and Physiological Psychology; }}{1967,63,23-33 \text {. }}$

Plemons, J. T., Willis, S. L., \& Baltes, P. B. Modifiability of fluid intelligence in aging. A short-term longitudinal training approach. Journal of Gerontology, 1978, 33, (2), 224-231.

Riegal, K. F,. \& Riegal, R. M. Development drop and death. Developmental Psychology, $1972, \underline{6}, 306-319$.

Roth, S., \& Bootzin, R. R. The effects of experimentally induced expectancies of external control: An investigation of learned helplessness. Journal of Personality and Social Psychology, 1974, 29, 255-264.

Roth, S., \& Kubal, T. Effects of noncontingent reinforcement on tasks of differing importance: Facilitation and learned helplessness. Journal of Personality and Social Psychology, $1975,32,680-6 \overline{91}$.

Schaie, K. W. Cross-sectional riethods in the study of psychological aspects of aging. Journal of Gerontology, 1959, 14, 208-215.

Schaie, K. W. A general model for the study of developmental problems. Psychological Bulletin, 1965, 14, 208-215.

Schaie, L. W., Labouvie, G. V., and Buech, B. V. Generational and cohort-specific differences in adult cognitive functioning: A fourteen-year study of independent couples. Developmental Psychology, 1973, 2, 151-166.

Schaie, K. W., \& Labouvie-Vief. Generational versus ontogenetic components of change in adult cognitive behavior: A fourteenyear cross-sequential study. Developmental Psychology, 1974, $10,3,305-320$.

Schultz, R. Effect of control and predictability on the physical and psychological well-being of the institutionalized aged. Journal of Personality and Social Psychology, 1976, 33, 563573 .

Seligman, M. E. P. Helplessness: On Depression, Development, and Death. San Francisco: Freeman, 1975. 
Seligman, M. E. P., \& Maier, S. F. Failure to escape traumatic shock. Journal of Experimental Psychology, 1967, 74, 1-9.

Siegler, I. C. \& Botwinick, J. A long-term longitudinal study of intellectual ability of older adults: The matter of selective subject attrition. Journal of Gerontology, $1979,34,(2), 242-245$.

Smith, J. M. A quick measure of achievement motivation. British Journal of Social and Clinical Psychology, 1973, 12, $\overline{137-143 .}$

Smith, J. M. Age differences in achievement motivation. British Journal of Social and Clinical Psychology, 1970, $\underline{9}, 1 \overline{75 .}$

Tennen, H., \& Eller, S. Attributional components of learned helplessness and facilitation. Journal of Personality and Social Psychology, 1977, 35, 265-271.

Thornton, J. W., \& Jacobs, P. D. The facilitating effects of prior inescapable unavoidable stress on intellectual

performance. Psychonomic Science, 1972, 26, 185-187.

Thurstone, L. L. Concealed figures (form A) Chicago: University of Chicago Press, 1950 .

Thurstone, L. L. Designs Princeton, N.J. Educational Testing Service, 1962 .

Thurstone, L. L. Punched Holes, Princeton, N.J., Educational Testing Service, 1962.

Thurstone, L. L., \& Thurstone, T. G. Primary Mental Abilities Chicago: Science Research Associates, 1950.

Veroff, J., Atkinson, J. W., Field, S., and Gurin, G. The use of thematic apperception to assess motivation in a nationwide interview study. Psychological Monographs, 1960, 24, 1-32.

Wallach, M. A., \& Kogan, M. Aspects of judgmental and decisionmaking: Interrelationships and changes with age. Behavioral Science, 1961, G, 23-36.

Wechsler, D. A. Manual for the Wechsler Adult Intelligence Scale. The Psychological Corporation, New York, 1955.

Weiner, B. (Ed.) Achievement, Motivation, and Attribution Theory. General Learning Press, Morristown, New Jersey, 1974. 
Weiner, B., \& Kukla, A. An attributional analysis of achievement motivation. Journal of Personality and Social Psychology, $1970,15,1-20$.

Weiner, B., Frieze, I., Kukla, A., Reed, L., Rest, S., \& Rosinbaum, R. M. Perceiving the Causes of Success and Failure. Morristown, N.J.: General Learning Press, 1971.

Wortman, C. B., Panciera, L., Shusterman, L., \& Hibscher, J. Attributions on causality and reactions to uncontrollable outcomes. Journal of Experimental Social Psychology, 1976, $12,301-316$. 
APPENDIX A

CONSENT FORM 


\section{CONSENT FORI:}

The purpose of this study is to investigate and develop information concerning the test of intellectual functioning. I understand that this first requires me to fill out questionnaires that deal with basic information on myself and my personal feelings about tests. Following this procedure, I will be asked to take short tests of intelligence. After the tests, I will be asked to fill out one last questionnaire that will ask my reactions, thoughts, and feelings toward certain aspects of this test and procedure.

I understand that this procedure does not contain any risks either physically or psychologically. I have been informed that I will receive five dollars for participating. I understand that I may withdraw at any time, and that such withdrawal will not penalize me in any way, including payment.

I further understand that this material will be used for research purposes only and that in this context all identities and individual data will be kept strictly confidential.

I understand fully the above matters and consent to participate in this study.

Signature

Date

Witness 
APPENDIX B

MARIABIAN NEED FOR ACHIEVEMENT SCALES 
PleAse use the Following SCALE tO INDICATE the DEgREE OF YOUR AGREEMENT OR DISAGREEMENT WITH EACH OF THE STATEMENTS ON THE FOLLOWING PAGES, RECORD YOUR ANSWERS IN THE SPACES PROVIDED BELOW.

+4 = VERY STRONG AGREEMENT

+3 = STRONG AGREEMENT

+2 = MODERATE AGREEMENT

$+1=$ SLIGHT AGREEMENT $0=$ NEITHER AGREEMENT NOR DISAGREEMENT

- 1 = SLIGHT DISAGREEMENT

- 2 = MODERATE DISAGREEMENT

-3 = STRONG DISAGREEMENT

- 4 = VERY STRONG DISAGREEMENT

1.

2.

3.

4.

5.

6.

7.

3.

9.

10.

11.

12.

13.
14.

15.

16.

17.

13.

19.

20.

21.

22.

23.

24.

25.

26.
27.

23.

29.

30.

31.

3?

33.

34.

35.

35.

37.

38. 
1. I USUALLY END UP CARRYING OUT THE THINGS I PLAN AT WORK,

2. I HAVE DIFFICULTY WORKING IN A NEW AND UNFAMILIAR SITUATION.

3. I AM VERY OPTIMISTIC ABOUT MY WORK CAREER.

4. I DON'T USUALYY TACKLE PROBLEMS THAT OTHERS HAVE FOUND TO BE DIFFICULT.

5. I AM HESITANT ABOUT MAKING IMPORTANT DECISIONS AT WORK.

6. The IDEA OF STRUgGling MY WAY TO THE tOP DOES NOT APPEAL TO ME,

7. I WOULD PREFER A JOB WHICH IS IMPORTANT, DIFFICJLT, AND INVOLVES A 50\% CHANCE OF FAILURE TO A JOB WHICH IS SOMEWHAT IMPORTANT BUT NOT DIFFICULT.

3. I AM USUALLY TEMPTED TO TAKE ON MORE RESPONSIBILITIES THAN A JOB ORIGINALLY ENTAILS,

9. THE THOUGHT OF HAVING TO TAKE ON A NEW JOB WOULD BOTHER ME.

10. I FIND IT ESPECIALLY SATISFYING TO COMPLETE AN IMPORTANT JOB THAT REQUIRED A LOT OF EFFORT.

11. I DON'T WORK WELL UNDER PRESSURE,

12. I BELIEVE THAT IF I TRY HARD ENOUGH, I WILL BE ABLE TO REACH MY GOALS IN LIFE,

13. I TAKE PRIDE IN MY WORK.

14. LEARNING NEW SKILLS DOESN'T EXCITE ME VERY MUCH.

15. I ONLY WORK AS HARD AS I HAVE TO.

1E. I TEND TO SET VERY DIFFICULT GOALS FOR MYSELF,

17. I LIKE TASKS THAT REQUIRE LITTLE EFFORT ONCE I'VE LEARNED THEM.

13. I AM AMBITIOUS.

19. I PREFER SMALL DAILY PRONECTS TO LONG-TERM ONES.

20. I REALLY ENJOY A JOB THAT INVOLVES OVERCOMING OBSTACLES,

21. I APPRECIATE OPPORTUNITIES TO DISCOVER MY OWN STRENGTHS AND WEAKNESSES,

22. I FIND LITTLE SATISFACTION IN WORKING HARD, 
23. THESE DAYS, I SEE LITTLE CHANCE FOR PROMOTION ON THE JOB UNLESS A PERSON GETS A BREAK.

24. SOLVING A SIMPLE PROBLEM IS NOT AS SATISFYING TO ME AS TRYING A DIFFICULT ONE.

25. I PREFER A JOB WHICH REQUIRES ORIGINAL THINKING.

26. I LIKE A JOB WHICH DOESN'T REQUIRE MY MAKINE RISKY DECISIONS,

27. I ONLY WORK BECAUSE I HAVE TO.

28. I OFTEN SUCCEED IN REACHING IMPORTANT GOALS I'VE SET FOR MYSELF,

29. I FEEL RELIEF RATHER THANS SATISFACTION WHEN I HAVE FINALLY COMPLETED A DIFFICULT TASK.

30. I PERFORM BEST IN COMPETITIVE SITUATIONS.

31. CONSTANT WORK TOWARD GOALS IS NOT MY IDEA OF A REWARDING LIFE,

32. I MORE OFTEN ATTEMPT DIFFICULT TASKS THAT I AM NOT SURE I CAN DO THAN EASIER TASKS I BELIEVE I CAN DO.

33. I AM NOT SATISFIED UNLESS I EXCEL IN MY WORK.

34. I DON'T LIKE TO HAVE THE RESPONSIBILITY OF HANDLING A DIFFICULT SITUATION.

35. I PREFER MY WORK TO BE FILLED WITH CHALLENGING TASKS,

36. WHEN I DO A JOB, I SET HIGH STANDARDS FOR MYSELF REGARDLESS OF WHAT OTHERS DO.

37. I TRY TO ANTICIPATE AND AVOID SITUATIONS WHERE THERE IS A MODERATE CHANCE OF FAILURE,

33. I WOUL RATHER DO SOMETHING AT WHICH I FEEL CONFIDENT AND RELAXED THAN SOMETHING WHICH IS CHALENGING AND DIFFICULT, 
APPENDIX C

DIRECTIONS TO TEST AND TEST 1 (SYNTHETIC) 
Study the series of numbers below. What number should come NEXT?

\section{2}

This series goes like this: $12 \quad 12 \quad 12 \quad 12$ The NEXT number in the series should be 1 . Put 1 in the blank next to the space as shown.

$$
12121212 \quad 1
$$

Now study the series of numbers below. Decide what the NEXT number should be.

$$
314415161
$$

The series goes like this: $\begin{array}{lllll}31 & 41 & 51 & 61 \text {. You should have answered } 7\end{array}$ as shown.

$$
\begin{array}{lllllllll}
\hline & 4 & 1 & 5 & 6 & 1 & 7
\end{array}
$$

Now study the series of numbers below. In each series, decide what the NEXT number should be.

$$
\begin{aligned}
& 343434 \\
& 11223344 \\
& 129349569789
\end{aligned}
$$

In the first row, the series goes like this: $\begin{array}{lllll}34 & 34 & 34 & \text { you should }\end{array}$ have answered 3 .

In the second row, the series goes like this: 112223344 . You should have answered 5 .

In the third row, the series goes like this: 129349569789 . You should have answered 10.

Now work the following problems for practice. Mark the NEXT number in each series.

$$
\begin{array}{lllllllll}
11 & 222233 & 34 & 4 \\
1928 & 19 & 2 & 8 & 1 & 9
\end{array}
$$

In the first row, the series goes like this: 11122233344 . You should have answered 4 .

In the second row, the series goes like this: 19281928192. You should have answered 8.

If you come to a problem you cannot work, skip it and go on to the next problem. If you have time, go back again to the hard problems. Work quickly, but try not to make mistakes. You will have 6 minutes for the test. You are not expected to finish in the time allowed. 
194126633892453

123123456456789

122635256025078

163594473152

789178927893789 287095680034115

32132132123

6309928734615

4227537960

54407346875621

22776954693500

381353819199

514399889612814

82196554174736

231721070399630

169680675546373

7117140

8972476

9258035799420537

17762726036

095780587974

358261739529889

7255261016311

7354665560200

2728520890386

35816048

8927256416682

003204183241516 
APPENDIX D

REASONING TEST (TEST 2) 
Study the series of letters below. What letter should come NEXT?

a $b$ a $b$ a $b$ a $b \quad 1$

This series goes like this: $a b$ ab ab ab. The NEXT letter in the series should be a. Put a in the blank next to the space as shown.

$$
a \quad b \text { a } b \text { a b a b } 1
$$

Now study the series of letters below. Decide what the NEXT letter should be.

$$
\text { c a d a e a f a } 2
$$

The series goes like this: ca da ea fa. You should have answered $g$ as shown.

$$
\text { c a d a e a f a } 2
$$

Now study the series of letters below. In each series, decide what the NEXT letter should be.

$$
\begin{array}{r}
c d c d c d 3 \\
a a b b c c d d 4 \\
a b \times c d \times e f \times g h \times 5
\end{array}
$$

In the first row, the series goes like this: cd cd cd. You should have answered $\mathbf{c}$.

In the second row, the series goes like this: a b b cc dd. You should have answered $\mathbf{e}$.

In the third row, the series goes like this: abx cdx efx ghx. You should have answered i.

Now work the following problems for practice. Mark the NEXT letter in each series.

$$
\begin{aligned}
& a a a b b b c c c d d 6 \\
& a \times b y a \times b y a \times b 7
\end{aligned}
$$

In the first row, the series goes like this: aaa bbb ccc dd. You should have answered $d$.

In the second row, the series goes like this: axby axby axb. You should have answered $\boldsymbol{y}$.

If you come to a problem you cannot work, skip it and go on to the next problem. If you have time, go back again to the hard problems. Work quickly, but try not to make mistakes. You will have 6 minutes for the test. You are not expected to finish in the time allowed. 
$a \times a y b \times b$ y $c \times c y d x d \quad 2$

$a b c a b c d e f d e i g h i 3$

a b c x y z d e f x y z g h i 4

$a b c a b d a b$ e a b f 5

$x y \times a \times y z b \times y z c \times y z \quad 6$

ef c g h c i jcklcm n 7

c b a c b a c b a c b 8

$a m b c m d e f m g h i j \quad 9$

a a c c e e g g i i 10

efefcdgh ghcdij 11

a b b c c c d d d d e e e e 12

a b c a b c d a b c d e 13

a b c c d e f f g h i i jk $1 \quad 14$

a b a c d c e f e ghg i j 15

a b c nod e f nog hino 16

$a b b b c d d d e f f f g h h \quad 17$

$$
\begin{array}{ll}
\text { h g f e c b } & 18 \\
\text { a c e g i km } & 19
\end{array}
$$

$a \times b$ y $c z a \times b$ y $c z a \times b \quad 20$

$a b b c d d e f f g h \quad 21$

$g h j k m n p q s t \vee w 22$

a b c a d e f d g h i g jk 123

a s b t c udve wf $x$ g 24

a a b b c d d e e f g g h 25

$a$ a b a b c c d c d e e f 26

a c f h k m p 27

V V V V V W W W W X X x y 28

$a b c c b c d e f f e d g h i \quad 29$

$a b c b c d e f g f g h$ i h 30 
APPENDIX E HIDDEN PATTERNS TEST (TEST 3) 


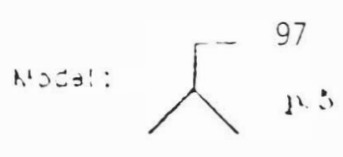

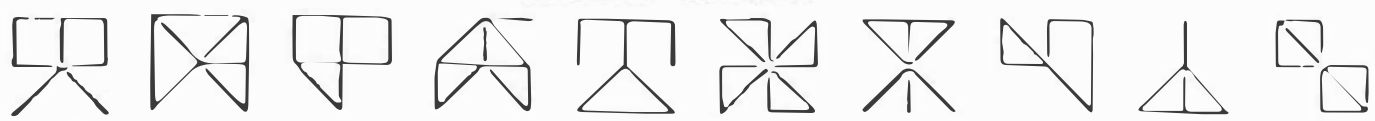

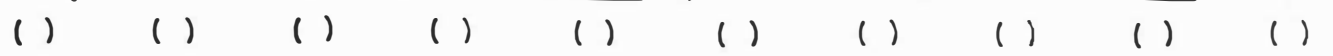

A .

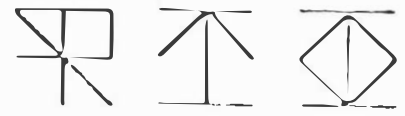

友

不
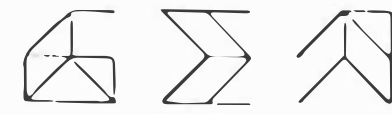

( ) 1

(

( )

( )

( )

( )

( )

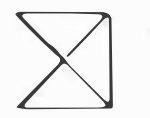

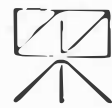
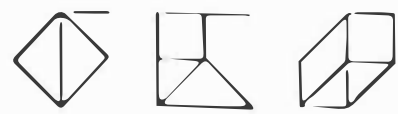

$4 \sqrt{17}$

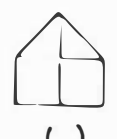

N7

$\frac{\lambda}{1}$

(1) 1

( )

( ) (1)

(1)

( )

()

( )

9

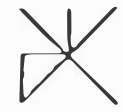

$M$

\begin{abstract}
( )
\end{abstract}
更

()

A (1)

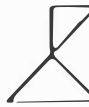

(1) (1)

$\triangle N$ 8

()

$\triangle$

(1) (1)

$M$

()

( )

( )

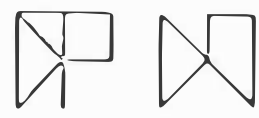

$\sqrt{1}$

( )

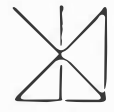

17

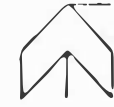

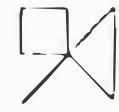

( ) ( )

( )

( )

( )

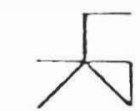

$S_{1}$

11

( )

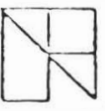

( )

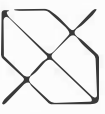

()
17

( )

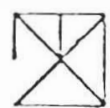

(1)

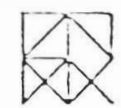

( )
ND

( ) ( ) 

$\sum_{(1)}^{X i} \sum_{(1)}$

叉诌 ( )

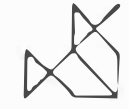

( )

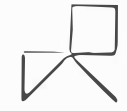

( )

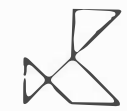

(1)

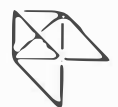

()

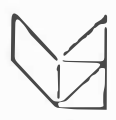

( )

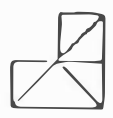

(1)

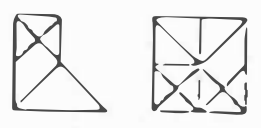

( )

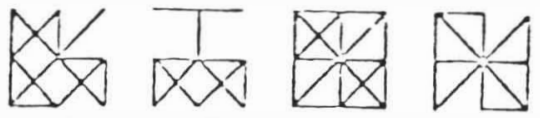
() ( )

( )
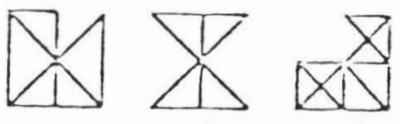

17

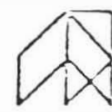

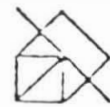

为

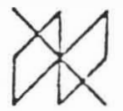

$1 / 1$

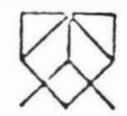

$x$

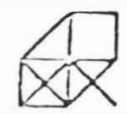

4

( )

( )

( )

( )

( )

( )

( )

10
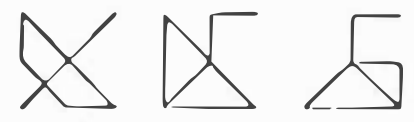

12
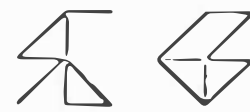

7

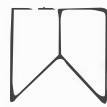

(1)

()

( )

$x$

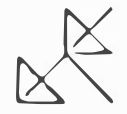

1
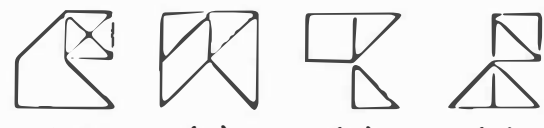

11

17

( )

$\lambda<$
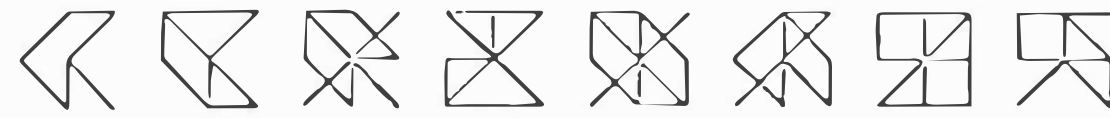

( )

( )

风

( )

( )

( )

( )

()

( )

( )
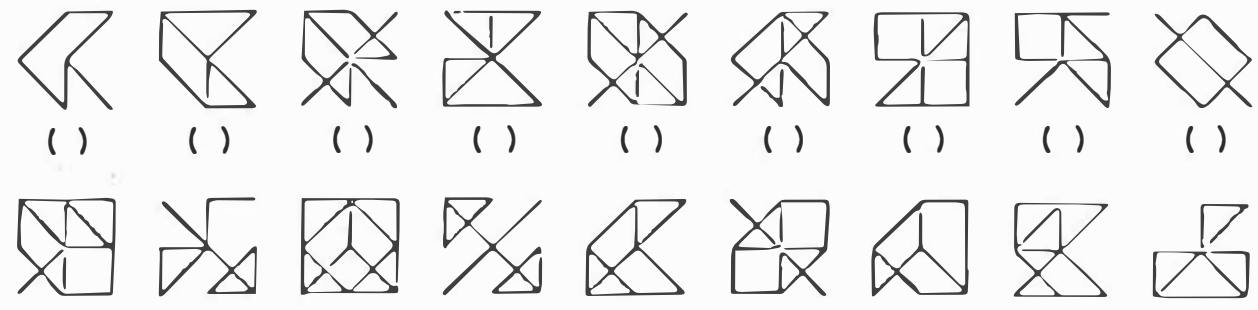

$\sqrt{1}$

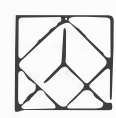

8

( )
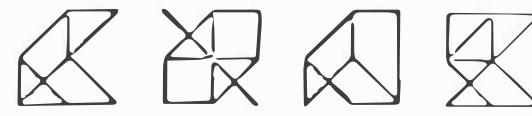

( )

( )

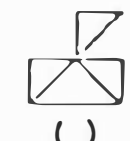

品双
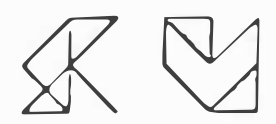

$\triangle A$

N

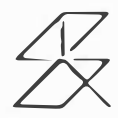

1

$\sqrt{1}$

( )

( )

( )

( )

( )

(1)

为

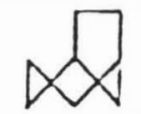

$\pi$
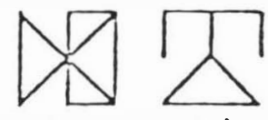

( )

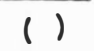

奴

(1)
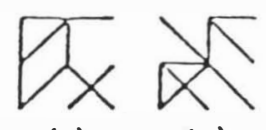

( )

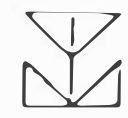

DO NOT CO OS TO THE REXT PLEE VNTIL RSIED TO DO SO. 
APPENDIX F

PAPER FOLDING TEST (TEST 4) 
In this test you are to inagine the folding and uniolding of झieves of paper. In each problew in the test there are some figures dram at tie lert of a vertical line and there are others drawn at the rigit of the inse. Tres figures at the lefi repiesent a square piece of paper being folded, and ire last of these figures has one or two stall circles drum on it to s'cos ::ter:a the paper has been punched. Each hole is punchea tiro'icis all the tischrasjes of paper at that point. One of the five figlires at the right oi travertical line shows where the holes will be when the faper is comoletely unfi:diz. Yo:1 are to decide wich one of these figures is correct and draid an $x$ t: figure.

Now try the sample problem below. (In this probles only one $\mathrm{k}=\mathrm{l}$ a $: \mathrm{a}$ s punched in tise folded paper.)

A
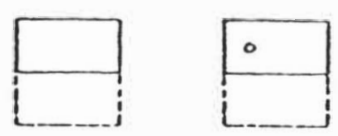

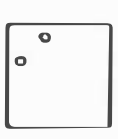

B

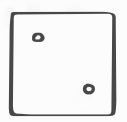

C

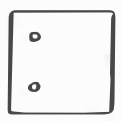

$\mathrm{D}$

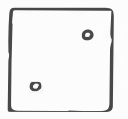

E

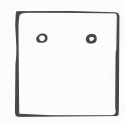

The correct answer to the sample problea above is $C$ and so it s=0:ild riave been marked with an $X$. The firkires below show now the paper was fo? why $C$ is the correct answer.
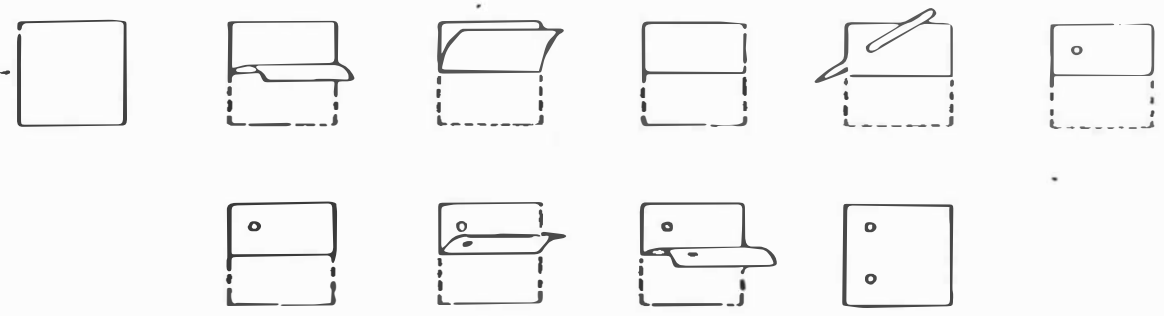

In these problems all of the folds that are male are shoin in t=ะ at the lert of the line, and the paper is not turned or zoved in $2 n j$ nay sucept to make the folds shown in the figures. Rewemer, the ansuer is the iare that shows the positions of the holes when the paper is completely

Your score on this test will be the numer marked correctly risicis a fraction of the number marked incorrectly. Therefore, it will not ica to yo:1r advantage to guess unless you are able to elininate one or rore of t:e ansiar choices as worg.

You will have 3 minutes for each of the tiso parts of this test. Eaci part has 1 page. Whel you have finisied Part 1, STOP. Please do not jo 0.1 to part 2 until you are asced to do so.

DO NOT TIKY THIS PAGE UNTIL ASKED TO DO SO. 
Part 1 (3 mirutes)

100

1. 13

$\begin{array}{lllll}A & \text { D } & C & D & \text { E }\end{array}$

$\square$

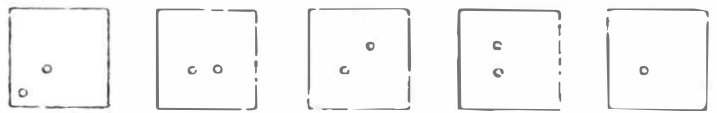

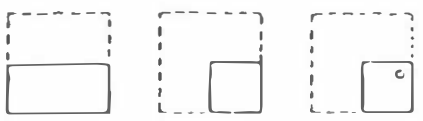

$\left[\begin{array}{ll}0 & 0\end{array}\right]\left[\begin{array}{ll}0 & 0 \\ 0 & 0\end{array}\right]\left[\begin{array}{ll|l}0 & 0 \\ 0 & 0 & 0\end{array}\right]$
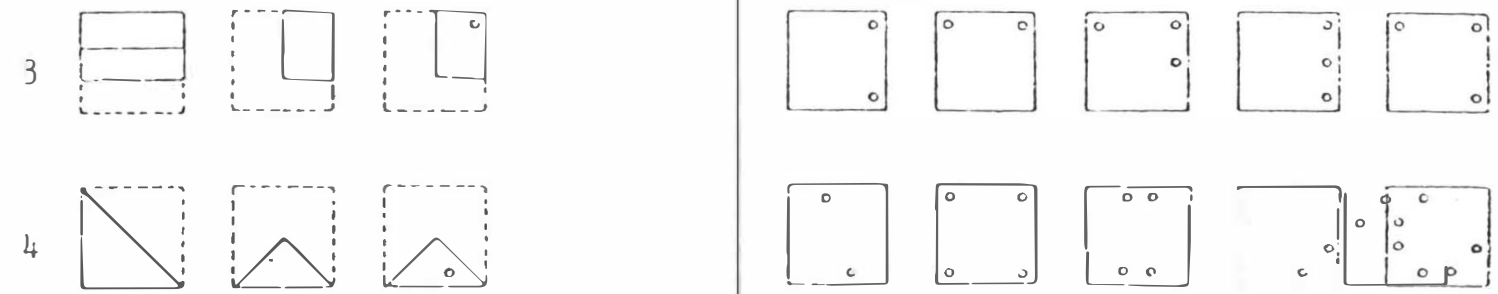

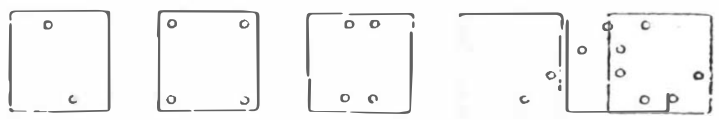
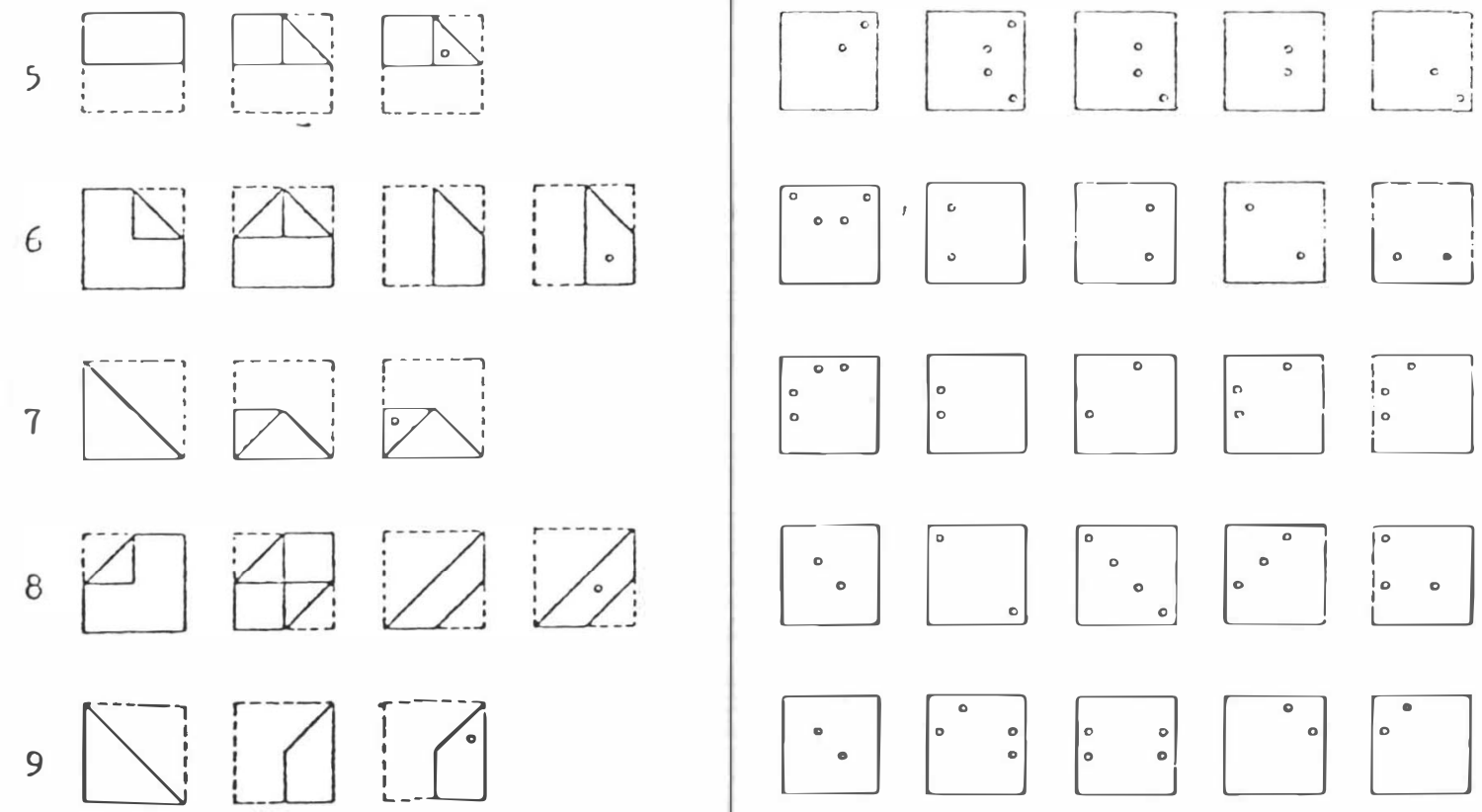

10
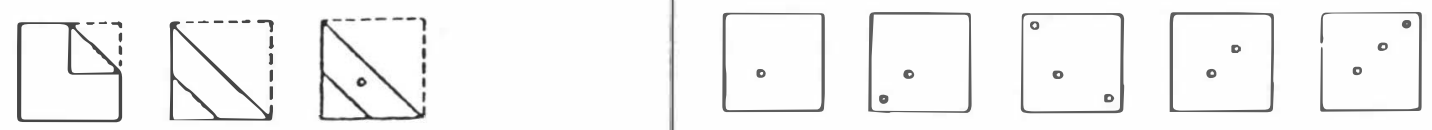
APPENDIX G

PRE-TEST ATTRIBUTION QUESTIONNAIRE 


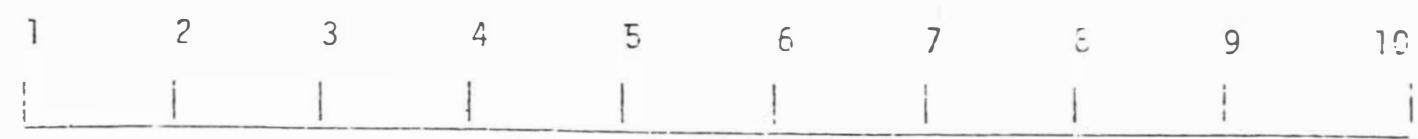

$=$ srioivi! siderabla roven.t.ənt

\section{Hizis ris:}

chonged
Hije sinonir.

consicerab? e dEvericration

How ingortant is it to you to do well on the test?

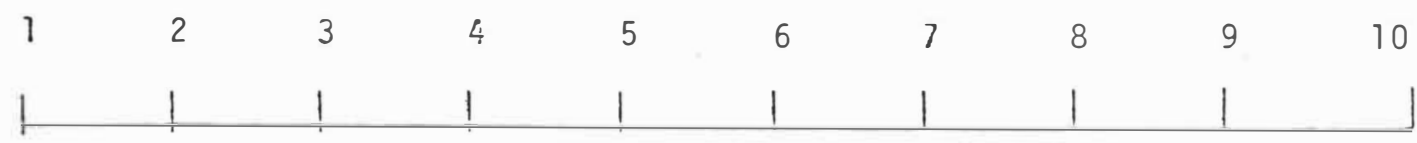

is riot

ortant

It is very

important

for me to

do well

to do

How important is it not to fail this test?

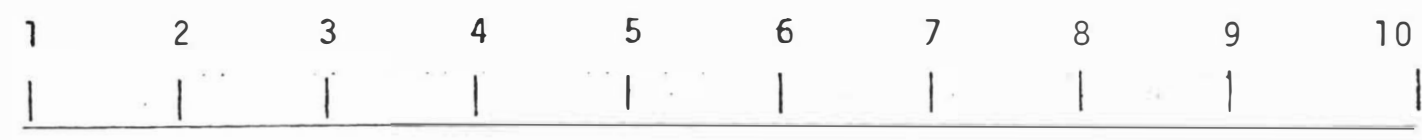

is of

impor-

It is very important not to fail ce whether

on such tests

Circle one of the responses below that best fits your attitude.

1. I am more concerned about doing well on a test than about failing a test.

2. I am more concerned aboutfailing a test than about doing well on a test.

3. I am equally concerned about not failing and doing well on tests.

4. When I take a test, I have no or little concern aboutfailing or doing well. 
APPENDIX H

POST FAILURE ATTRIBUTION QUESTIONNAIRE 


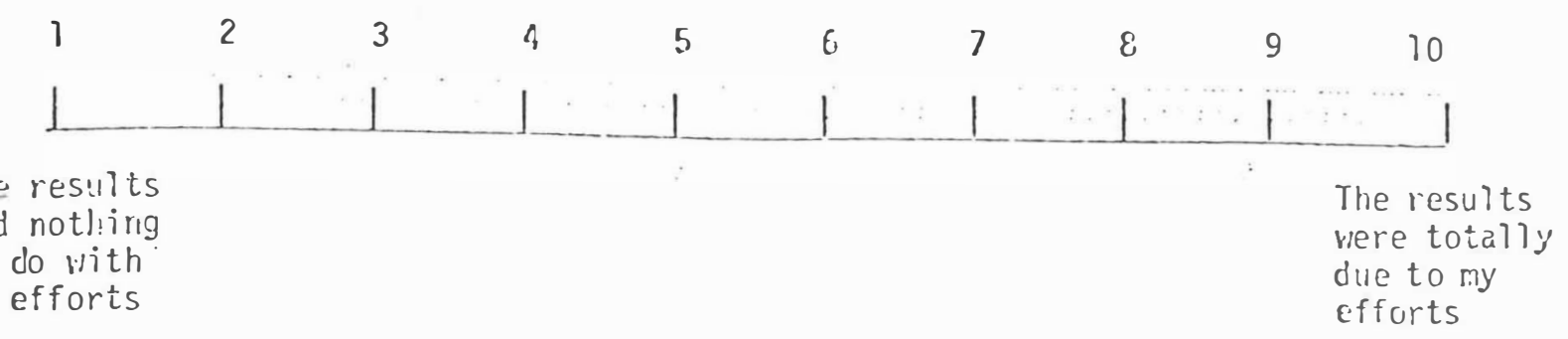

To what extent did task difficulty play a part in the outcome?

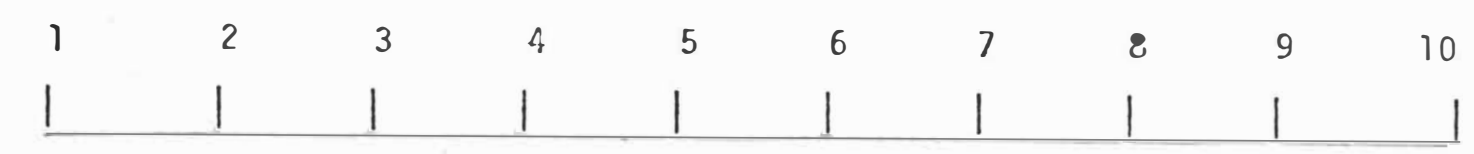

e results

d nothing

do with

e task

fficulty

The results vere totally' due to the diff icult.y' of the task

How hard did jou try to succeed at this task?

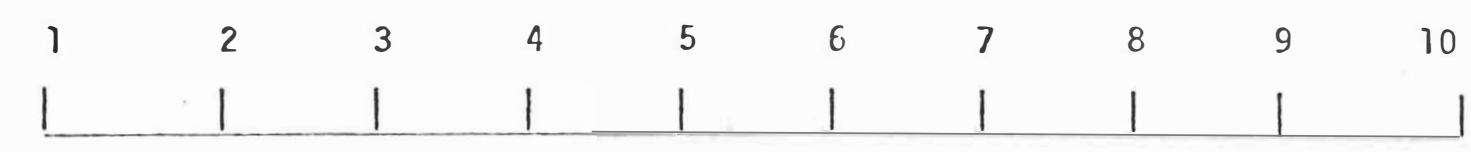

\section{treme?y}

in effort

Average

effort
Extremely

high effort

How important was it to you to do well at this task?

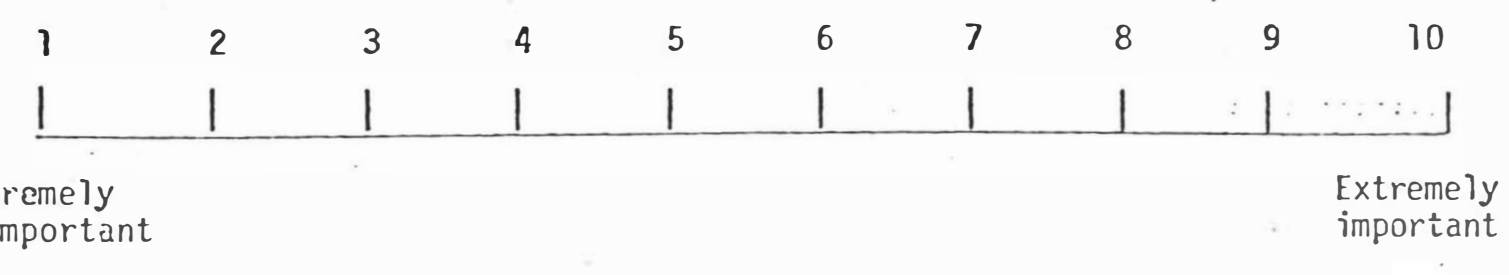


APPENDIX I

FINAL ATTRIBUTION QUESTIONNAIRE 
b'ould you evaluate your score as a success or as a failure?

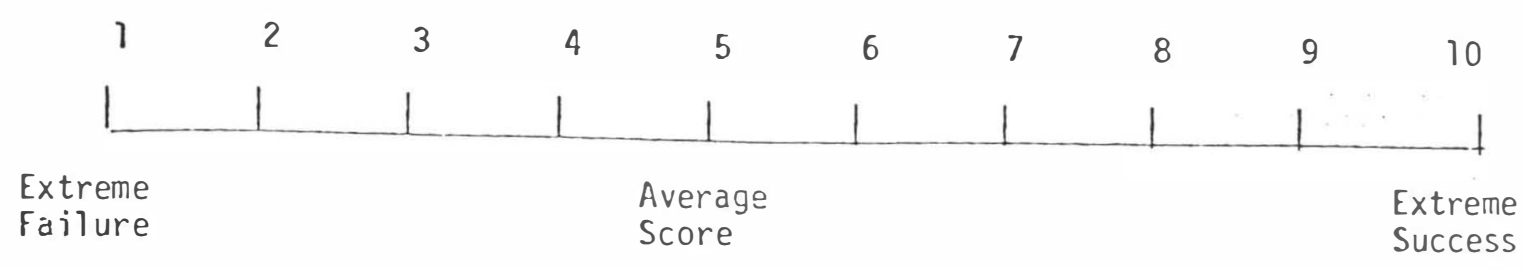

Do you think you did better or worse than you expected?

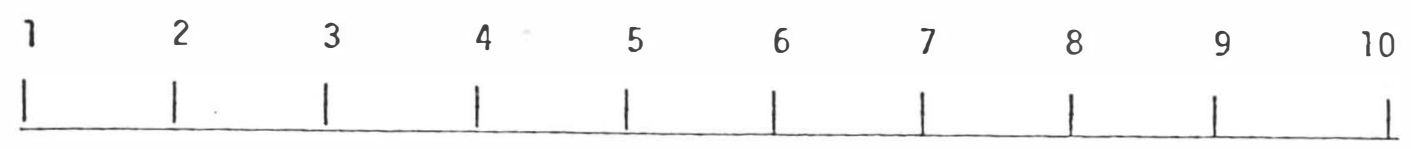

Much Worse

Than I

Expected
Exactly

What I

Expected
Much Better

Than I

Expected

To what extent did luck play a part in the outcome?

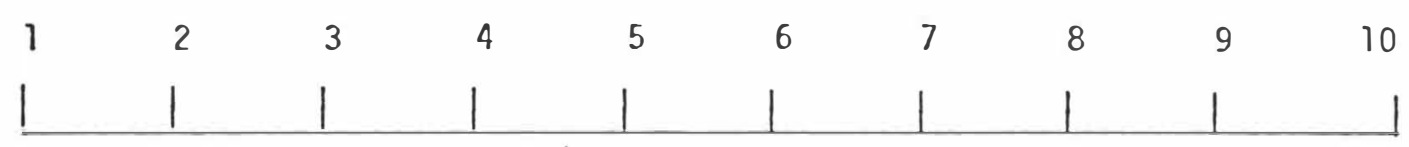

Luck good

or bad had

nothing to

do with the

outcome

The outcome was a total matter of good or bad luck

To what extent did your intellectual ability play a part in the outcome?

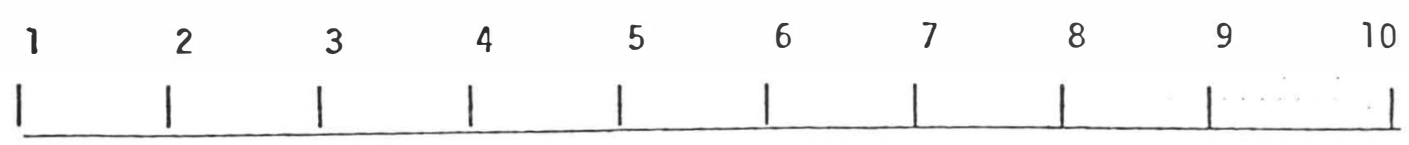

The results

had nothing

to do with

my ability 


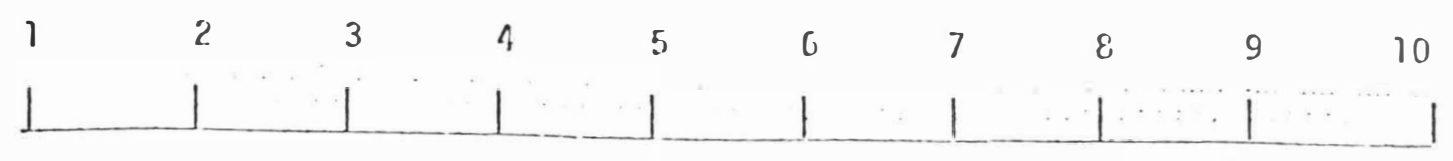

he results

ad nothing

o do with

The results were totiilly

due to my

efforts

To what extent did task difficulty play a part in the outcome?

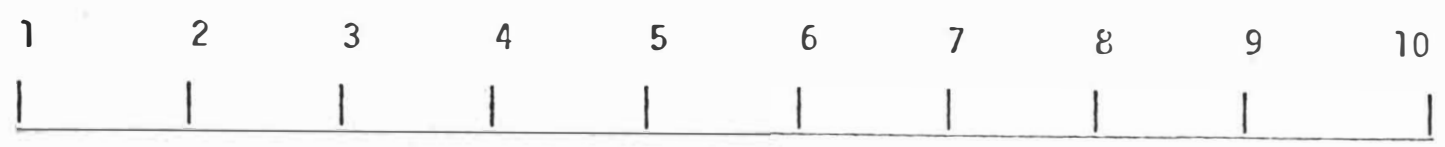

The results

iad nothing

to do with

the task

Jifficulty

The results viere totally due to the difficulty of the task

How hard did you try to succeed at this task?

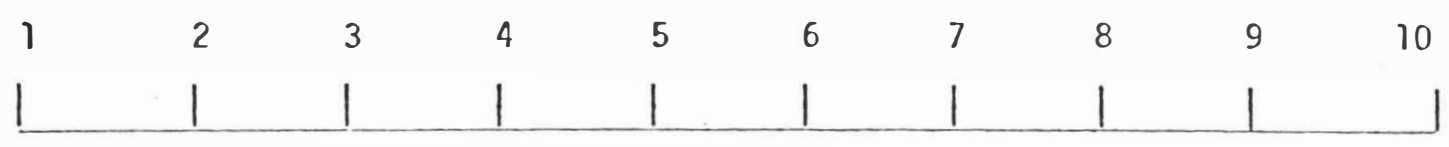

Extreme?y

lo:t effort
Average

effort
Extremely

high effort

How important vas it to you to do well at this task?

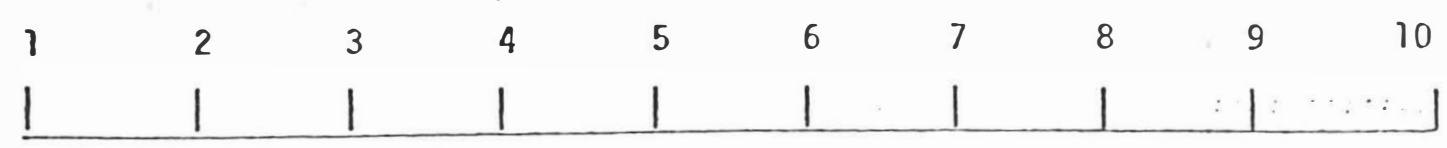




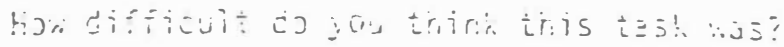

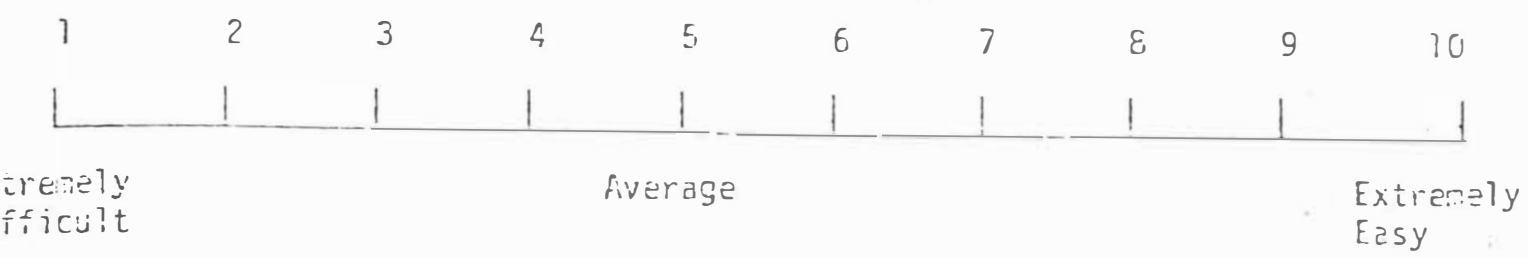

liere you Tucky or uniucky on the $i \equiv s \dot{i}$ ?

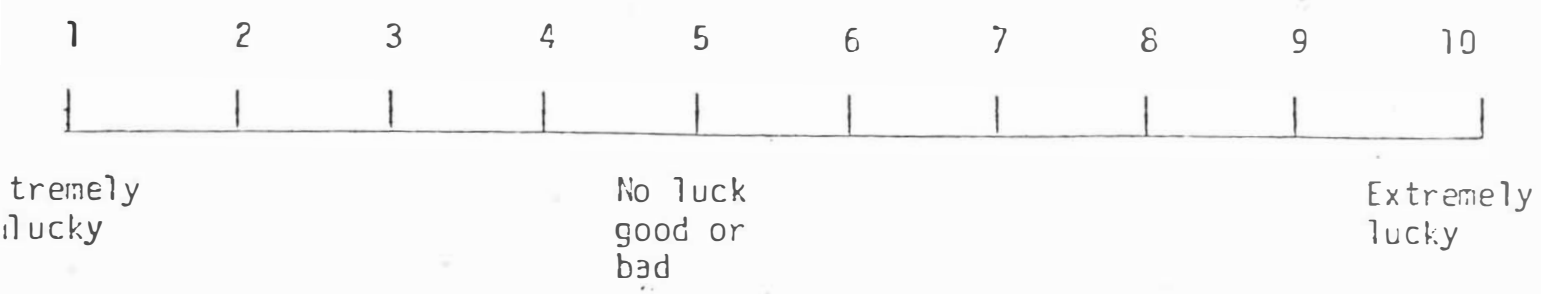

How intelligent do jou think you are?

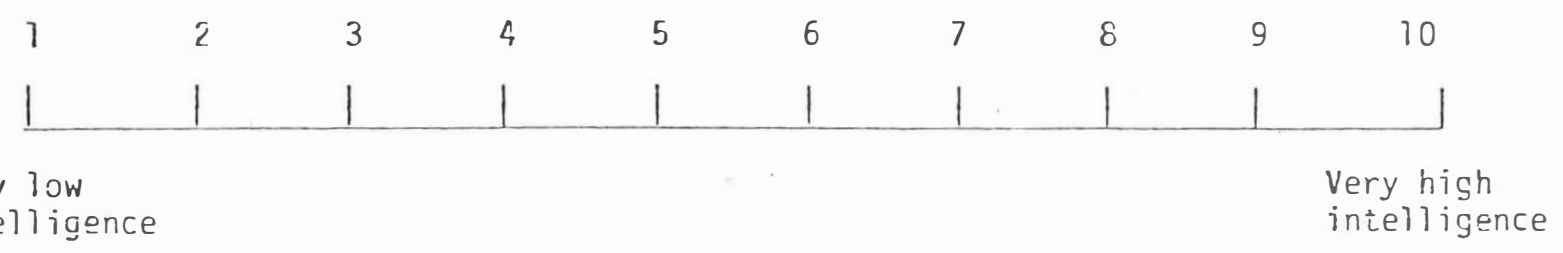

How rell do you expect to do in future tests?

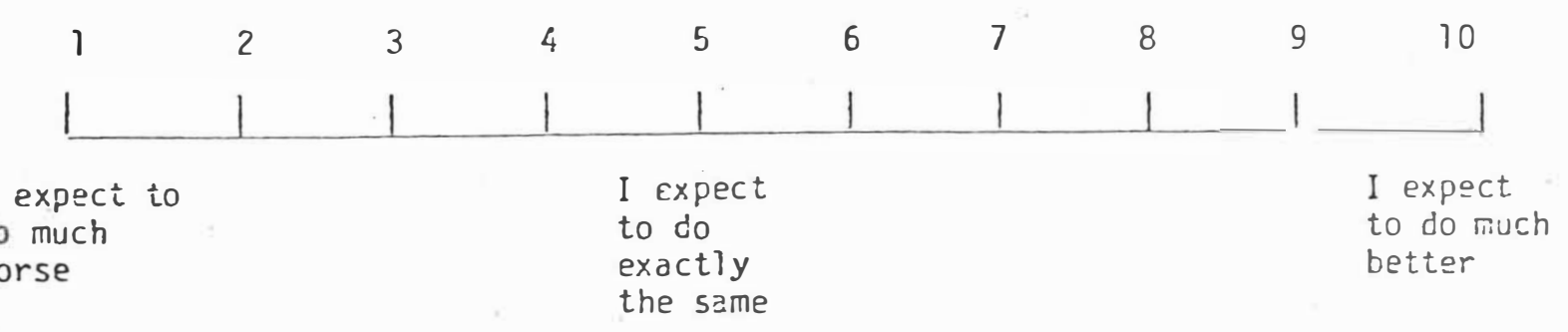


APPENDIX J

RELEASE OF INFORMATION AND PAYMENT FORM 
I have participated in this study and understand its purpose. I realize that the test used in this study was not a test of intelligence, nor does it reflect my intelligence in any way. I understand the information as to my success and failure was independent of my answers and would have been negative regardless of my answer.

I have been shown the purpose of this study and understand that it required this negative information.

(signature)

I have been paid five dollars $(\$ 5)$ as agreed upon for participating in this study.

(signature)

(date)

(witness) 
Vita

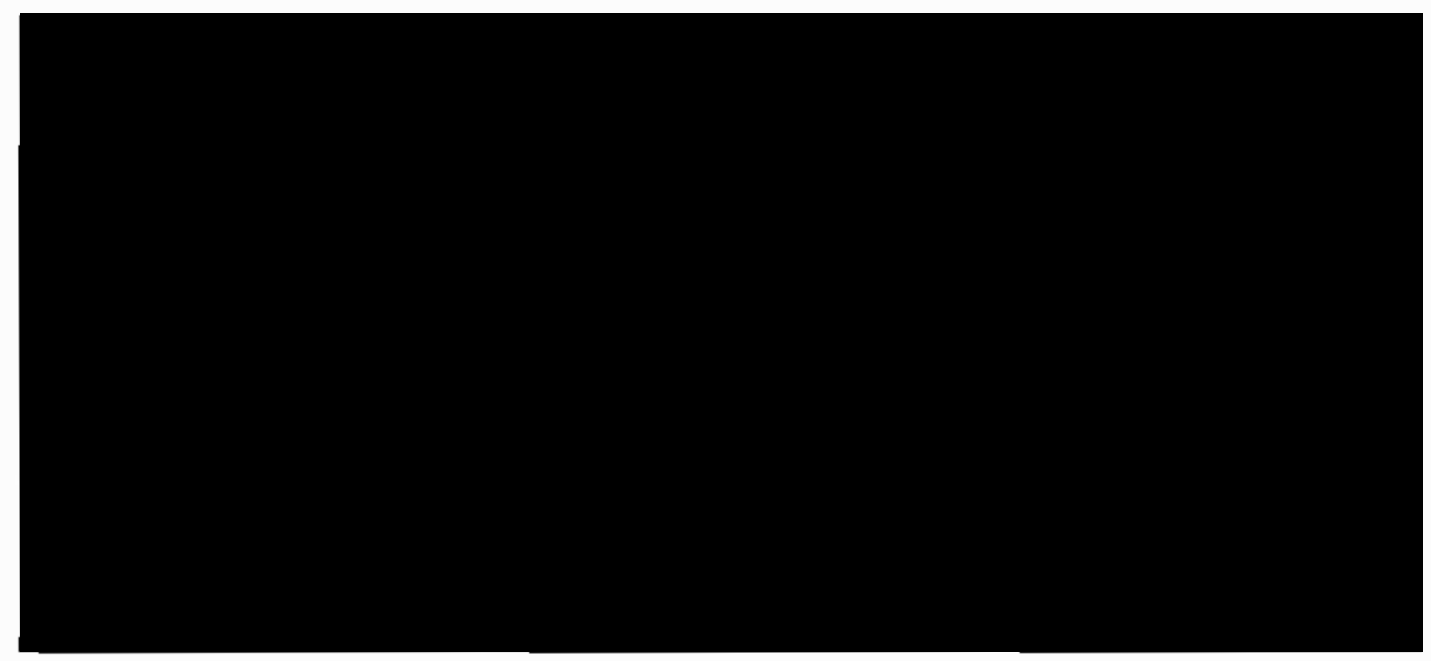

